The effect of intumescent mat on post-fire performance of carbon fibre reinforced composites

$$
\text { Zhu, C., Li, J., Clement, M., Yi, X., Rudd, C., Liu, X. }
$$

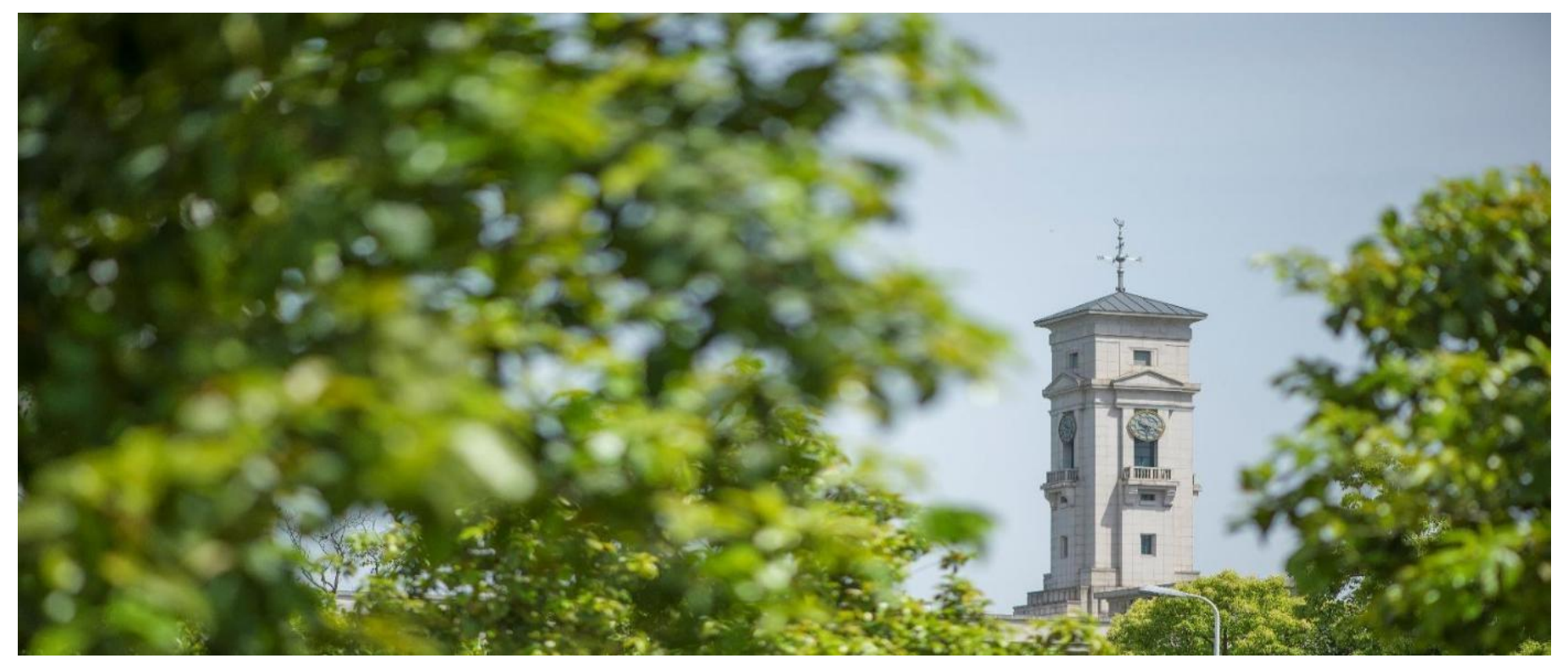


University of Nottingham Ningbo China, 199 Taikang East Road, Ningbo, China

First published 2019

This work is made available under the terms of the Creative Commons Attribution 4.0 International License:

http://creativecommons.org/licenses/by/4.0

The work is licenced to the University of Nottingham Ningbo China under the Global University Publication Licence:

https://www.nottingham.edu.cn/en/library/documents/researchsupport/global-university-publications-licence.pdf 


\title{
The effect of intumescent mat on post-fire performance of carbon fibre reinforced composites
}

\author{
Chenkai Zhu ${ }^{1}$, Jingjing Li ${ }^{1}$, Mandy Clement ${ }^{2}$, Xiaosu Yi ${ }^{1}$, Chris Rudd ${ }^{1}$, Xiaoling Liu ${ }^{1 *}$ \\ ${ }^{1}$ University of Nottingham Ningbo China, 199 Taikang East Road, Ningbo, 315100, China ${ }^{2}$ \\ Technical Fibre Products Ltd, Burneside Mills, Kendal, Cumbria, LA96PZ, UK \\ * Correspondence: Xiaoling.Liu@nottingham.edu.cn; Tel.: +86-0574-8818-0000 (8057)
}

\begin{abstract}
:
This study investigated the effect of intumescent mats (M1 and M2) with different compositions on the post-fire performance of carbon fibre reinforced composites (CFRP). The sandwich structure was designed for composites where M1 (CFRP-M1) or M2 (CFRP-M2) mats were covered on the composite surface. A significant reduction in the peak heat release rate (PHRR) and total heat release (THR) was observed from the cone calorimetric data and CFRP-M1 composite showed the lowest value of $148 \mathrm{KW} / \mathrm{m}^{2}$ and $29 \mathrm{MJ} / \mathrm{m}^{2}$ for PHRR and THR, respectively. Additionally, a minor influence on mechanical properties was observed due to the variation of composite thickness and resin volume in the composite. The post-fire properties of composite were characterised and the M1 mat presented better retention of flexural strength and modulus. The feasibility of two-layer model was confirmed to predict the post-fire performance of composites and reduce the reliance on the large amounts of empirical data.
\end{abstract}

\section{Keywords:}

Composites, Post-fire performance, flame retardant, Intumescent mats 


\section{Introduction}

Polymer composites due to their low weight to strength ratio, good mechanical behaviour, chemical resistance and corrosion resistance, find mammoth applications in automotive, aircraft, airspace, marine and civil construction ${ }^{1,2}$. Epoxy resin is widely used as matrix in advanced composite due to its good impregnation and adhesion to fibre reinforcement, resulting in excellent chemical and mechanical performance and low shrinkage on cure ${ }^{3}$, 4 . However, its flame retardant behaviour raises a serious safety issue on the use of polymer composites due to the extreme flammability of polymer matrix of the composite when compared with traditional structure material such as steel and alloy ${ }^{5,6}$. As such, the flammability of epoxy resins still represents a limitation in the structural application as an incidental fire event will lead to health risks ${ }^{7}$.

To meet application requirement, the flame retardant performance of composites should be improved but the conventional approach is to add the addition of a flame retardant agent into the resin matrix to disrupt the combustion cycle which requires sufficient heat, oxygen and combusting materials 8,9 . The successful commercial flame retardants for polymer matrix with effective performance are halogenated flame retardants such as tetrabromobisphenol (TBBPA) ${ }^{10}$, the release of smoke, carbon monoxide and corrosive gases (namely $\mathrm{HBr}$ ) during the burning results in environmental effect with health hazards ${ }^{9-11}$. Furthermore, the alternative flame retardants such as phosphorus and inorganic based, present a significant negative impact on mechanical behaviour which is mainly expressed regarding tensile behaviour, flexural properties and impact properties ${ }^{12-14}$.

Therefore, the current demand for flame retardant composite not only is the effective flame retardancy without toxic gas release, but also requires the high mechanical properties with good properties retention for most type of fire ${ }^{15-17}$. The most effective approach to protect the composite against fire without altering intrinsic properties (mechanical properties) is the use of fire-retardant barrier on the material surface such as the intumescent coating 18,19 and insulative fabrics 20,21 , as passive fireproofing, to delay the onset of combustion, reduce heat transfer from the fire to the composite structure, and minimise the effect on the mechanical performance of composite 22,23 .

Currently, the expandable graphite has become an attractive material for surface flame retardant application, as it is able to decompose and release large volumes of gases to cause expansion in the direction perpendicular to the surface exposed to the fire, as such creating a protective dense char layer which inhibits the diffusion of heat and oxygen into the polymer matrix and prevents the flame from spreading 
According to the literature, the recent research on flame retardant composite is focused on the fire reaction properties of composite 5,12 . However, much less information is available on the post-fire performance of composites during fire, and rare international standard is available on composite mechanical properties characterisation within/after burning ${ }^{27}$. However, it is important to consider the mechanical performance and failure resistance in the event of fire when using the composite in load-bearing structures. Decomposition, softening, cracking of the polymer matrix such as the epoxy due to fire can reduce the composite mechanical performance rapidly, and lead to distorting, buckling and collapse of composite structure ${ }^{28}$.

The purpose of this study is to assess the effect of intumescent mat on the flexural properties of composites during fire exposure, study the validation of composite model, which was proposed by Mouritz et al. ${ }^{29}$, to predict the flexural properties and failure of composite laminates with intumescent mats on the surface. The artificial fire tests were performed using the radiant heater in cone calorimeter and the flexural strength and modulus of composites were determined at room temperature after the fire test, then the flame retardant performance of intumescent mat was figured out.

\section{Materials and Methods}

\section{Composite preparation}

The material used for composite manufacture includes carbon fibre $(\mathrm{CF})$ reinforced epoxy prepreg (ACC (Beijing) Science \& Technology, China) and intumescent mat (Technical Fibre Products (TFP), UK), with the details listed in the Table 1.

Table 1: The specification details of prepreg and intumescent mats (M1 and M2) in this study.

\begin{tabular}{|c|c|c|c|c|c|c|c|}
\hline Materials & $\begin{array}{c}\text { Thickness } \\
(\mathrm{mm})\end{array}$ & $\begin{array}{c}\text { Areal } \\
\text { weight } \\
\left(\mathrm{g} / \mathrm{m}^{2}\right)\end{array}$ & $\begin{array}{c}\mathrm{CF} \\
(\mathrm{wt} \%)\end{array}$ & $\begin{array}{c}\text { Glass } \\
\text { fibres } \\
(\mathrm{wt} \%)\end{array}$ & $\begin{array}{c}\text { Expandable } \\
\text { graphite } \\
(\mathrm{wt} \%)\end{array}$ & $\begin{array}{c}\text { Mineral } \\
\text { fibres } \\
(\mathrm{wt} \%)\end{array}$ & $\begin{array}{c}\text { Expansion } \\
\text { ratio }\end{array}$ \\
\hline Preperg & 0.2 & 345 & 58 & $/$ & $/$ & $/$ & $/$ \\
\hline M1 & 0.5 & 164 & $/$ & $45-40$ & $10-40$ & $20-50$ & $20: 1$ \\
\hline M2 & 0.5 & 100 & $/$ & $53-55$ & $39-43$ & $/$ & $10: 1$ \\
\hline
\end{tabular}


Three composite compositions were designed in this study (shown in Table 2). As can

be seen from the

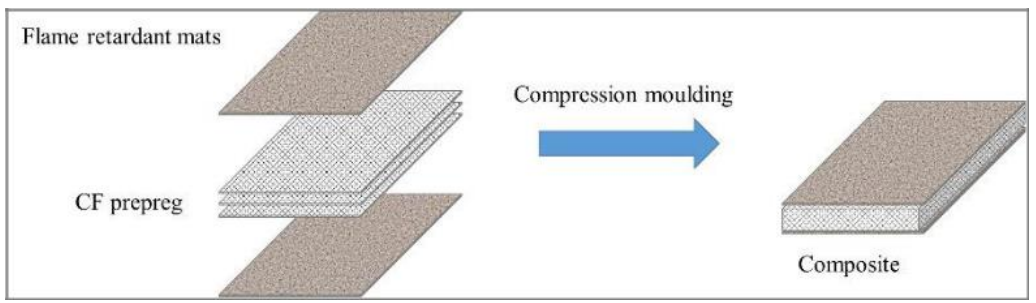

Figure 1 the flame retardant composites were designed as sandwich-like structure; the intumescent mat was covered on the composite surface and manufactured via the compression moulding with 2 hours curing period at $5 \mathrm{MPa}$ pressure and $130{ }^{\circ} \mathrm{C}$ curing temperature. The resin in prepreg impregnated mats under pressure and combined the mat with core $\mathrm{CF}$ prepreg to be integrated composite. The final composites produced were cut into required dimension for flame retardant and mechanical characterisation.

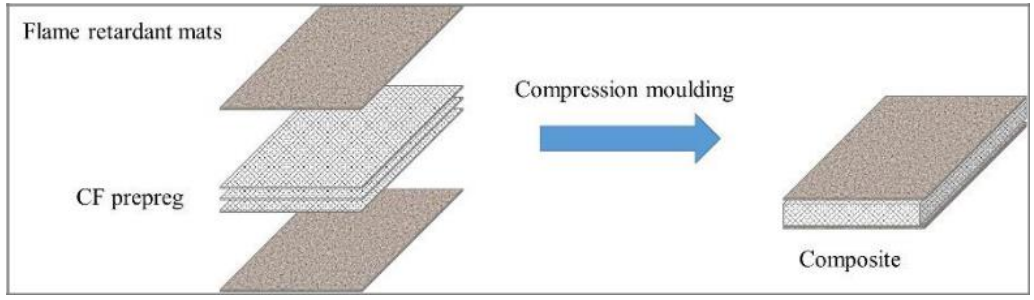

Figure 1: The scheme of structure design and manufacture process of flame retardant composite.

Table 2: The composition of composites in this study.

\begin{tabular}{|c|c|c|c|c|c|c|c|}
\hline \multirow{2}{*}{ Sample code } & \multirow{2}{*}{$\begin{array}{c}\text { Thickness } \\
(\mathrm{mm})\end{array}$} & \multicolumn{3}{|c|}{$\begin{array}{c}\text { Composition } \\
\text { (Plies) }\end{array}$} & \multicolumn{3}{c|}{$\begin{array}{c}\text { Composition } \\
\text { (Mass Percent \%) }\end{array}$} \\
\cline { 3 - 8 } & & Prepreg & M1 & M2 & CF & Resin & M1/M2 \\
\hline CFRP & 3.01 & 14 & $/$ & $/$ & 58 & 42 & $/$ \\
\hline CFRP-M1 & 3.25 & 14 & 2 & $/$ & 55 & 39 & 6 \\
\hline CFRP-M2 & 3.14 & 14 & $/$ & 2 & 56 & 40 & 4 \\
\hline
\end{tabular}

\section{Flammability test}

In order to assess the fire behaviours of the composite with intumescent mats, the $100 \mathrm{~mm} \times 100 \mathrm{~mm}$ specimens were exposed to an incident heat flux of $50 \mathrm{~kW} / \mathrm{m}^{2}$ using cone calorimeter (Fire Testing Technology Ltd, UK) according to the ISO5660-1 standard.

For the post-fire performance of composites study, the triplicate composite specimens of each group were exposed to $50 \mathrm{~kW} / \mathrm{m}^{2}$ for $300 \mathrm{~s}$, after which they were cooled to the ambient temperatures before their flexural properties were determined. 


\section{Flexural properties analysis}

The flexural strength and modulus of composites before flammability test were determined at room temperature using three-point bending tests according to the ISO 14125 standard. The specimens were loaded using the MTS universal testing machine (E45) with $50 \mathrm{KN}$ load cell and crosshead of $2 \mathrm{~mm} / \mathrm{min}$.

For the composite of post-fire performance test, the surface of specimens which were exposed to the heat was placed against the load point in the three-point bend test. As such the heat-damaged surface of the composite was subject to a bending - induced compressive stress.

The flexwral strength ( ) and modulus ( ) of the specimens were calculated using:

Where was the flexural stress at midpoint $(\mathrm{MPa}),(\mathrm{N})$,

was the support span length $(\mathrm{mm})$, and the beam.

was the load at a given point were the width and thickness of

$$
\left.-\overline{{ }_{4}(\Delta)} \bar{\Delta}\right)
$$

Where was the flexural modulus of elasticity (MPa), $\Delta$ was the difference, in deflection bețween s' and s', which were the beam mid-point deflections during plastic deformation $(\mathrm{mm}), \Delta$ is the difference in load $\mathrm{F}^{\prime}$ and load $\mathrm{F}$ at $\mathrm{s}$ and $\mathrm{s}$ respectively.

\section{Microstructure analysis}

Fire damage to the composite was observed after testing in the cone calorimeter using the optical microscope (NE930, NexCope ${ }^{\circledR}$, China) firstly. The image of cross-section for each composite samples with different time-point was captured using the software (Version 9.0, shareware). The delamination and depth of burnt layer could be measured directly.

After that, the cross-section of the composite was sputtered with $10 \mathrm{~nm}$ gold using the high vacuum film deposition systems (EM SCD500, Leica ${ }^{\circledR}$, Germany). The sputtered samples were imaged using the scanning electron microscopes (Sigma VP, Zeiss ${ }^{\circledR}$, Germany) in secondary electron mode, with $10 \mathrm{KV}$ voltage.

\section{Statistical analysis}

Statistical analysis was performed with GraphPad Prism (version 7.00, GraphPad Software, San Diego, CA, U.S.A) with unpaired t-tests. Confidence level was $95 \%$. 


\section{Modelling for post-fire performance of composite}

Normally, when the polymer composite is exposed to the heat for a sufficient period, the resin is able to degrade and pyrolysis, and thermal damage in the form of charring and delamination. The char in the burnt layer is defined as the carbonaceous residual material from the resin matrix which is combusted and degraded after the thermal degradation process.

Mouritz et al. ${ }^{27,28}$ have developed a model to simulate the post-fire performance of composite. As can been seen in

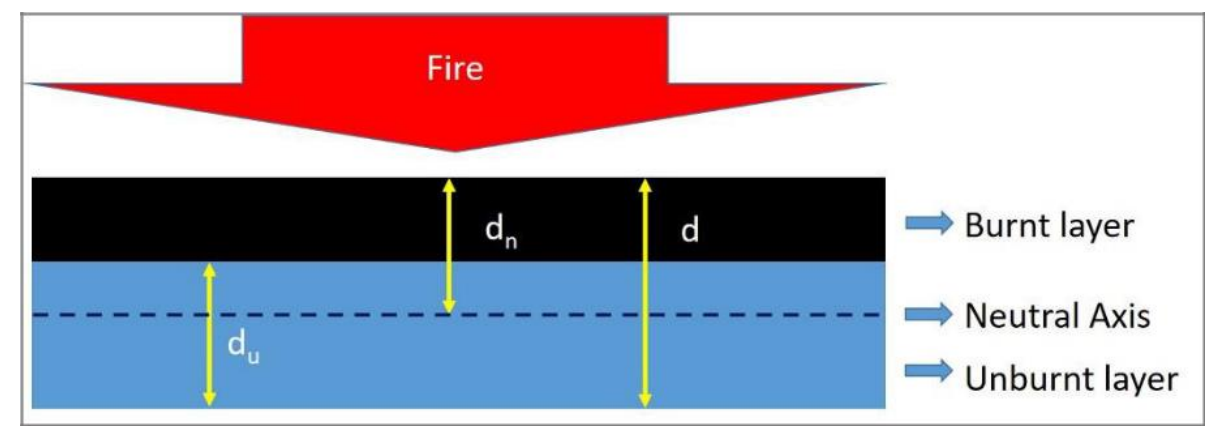

Figure 2, when the polymer composite was under the uniform heat over one surface, the fire damage would extend through along the material with an even, well-defined combustion. Then the fire damaged composite could be defined as a two-layer material with burnt layer and unburnt layer. It is assumed that the mechanical properties of burnt layer are negligible whilst unburnt zone has the same mechanical properties as the original (pre-fire) composite materials, because it is considered that thermal softening (prior to decomposition) of the matrix is fully recovered when cooled to room temperature 29 .

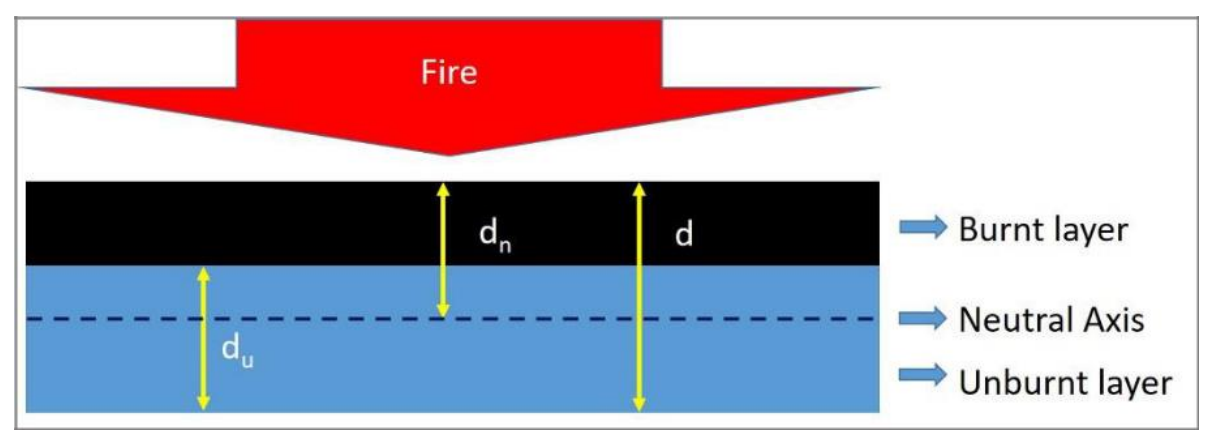

Figure 2: the schematic of composite under the fire burning, one layer being the burnt region with char and the second layer is the unburnt region. Where, the is the thickness of the sample, is the thickness of the unburnt layer and is the neutral axis. 
As such, to simulate the mechanical properties of composites after burning, the composite structure is assumed as a long, slender beam of uniform properties loaded symmetrically in the three-point bending configuration 27,30 . The bending moment $\mathrm{M}$ of the fire-damaged composites can be determined by solving:

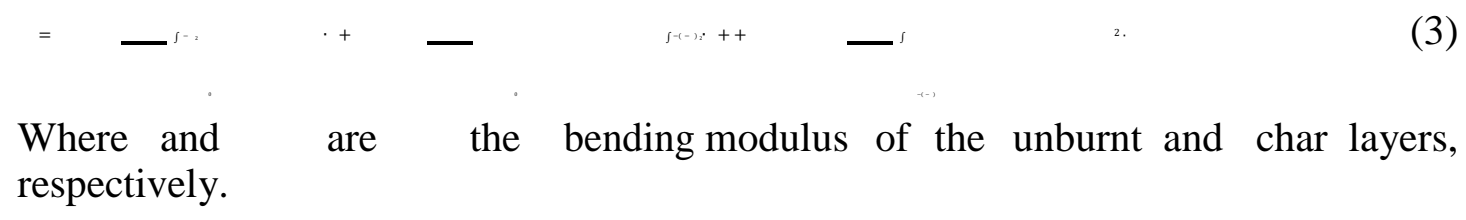

Where and are the bending modulus of the unburnt and char layers, respectively.

Then, solving Equation 3 will introduce the moment:

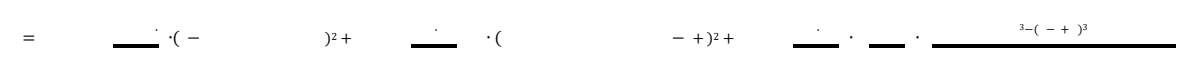

Additionally, the neutral axis can be calculated based on the research by Mouritz et al. 27:

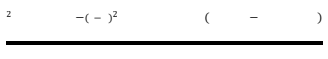

The failure load is then determined by equation below ${ }^{27}$ :

For the case where the flexural properties of the burnt layer are negligible, then Equation 6 is reduced to:

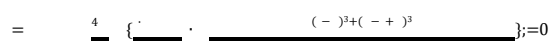

Then, the apparent flexural strength of a fire-damaged material is given by:

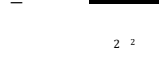

After simplifying equation 3 with the second moment of area theory, the apparent flexural modulus of a fire-damaged composite is determined using:

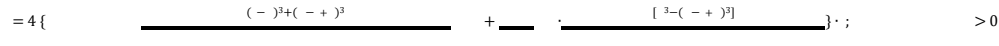

For the case where the flexural properties of the char layer are negligible, then this equation reduces to: 


\section{Results and discussion}

\section{Flammability test}

Flammability test of the composite samples was performed using cone calorimetry with the heat flux of $50 \mathrm{~kW} / \mathrm{m}^{2}$, the fire performance parameters including time-to ignition (TTI), the heat release rate (HRR), the peak value of heat release rate (PHRR), the time to the peak value (TPHRR), the total heat release (THR) and the mass loss rate (MLR) were presented in Table 3.

The composite with one layer intumescent mat (M1 \& M2) covering had presented relatively high time-to-ignition values, low PHRR, THR and MLR value, and higher value of time period to reach PHRR. This suggested that the M1 and M2 mats used in the manner employed in this study not only reduced the flammability of composite under the heat, but also delayed the fire ignition. Kandare et al. analysed the properties of intumescent mats in their research and found interesting results. They demonstrate that the TTI value was reduced when intumescent mat was combined with core composite via resin infusion process ${ }^{31}$, but that was increased when mat was bonded onto the core composite using a few drops of resin ${ }^{21}$. As such, this difference on the flame retardancy could be attributed to the resin volume in the mat. The resin infusion process was able to introduce lots of resin into the mats with full impregnation, which should be much more than the volume of resin used to bond the mat onto the composite with smooth surface. However, the mat bonded on the surface with a little resin could result in the rough surface and imperfect impregnation with flaws inside.

In this study, the process for composite manufacturing was to use compression moulding with CF prepreg and dry mat. Compared with CFRP control group, no extra resin was introduced into the CFRP-M1 and CFRP-M2 composite, the M1 or M2 mats on the composite surface were impregnated with resin squeezed from the composite prepreg under the pressure of $\sim 5 \mathrm{MPa}$. According to the results, the TTI value of CFRP composite was increased from $45 \mathrm{~s}$ to $109 \mathrm{~s}$ and $91 \mathrm{~s}$ for CFRP-M1 and CFRP-M2, respectively, and the composite surface was smooth with full impregnation.

Based on the composition of M1 and M2 mats in Table 1, no obvious and significant relationship between the thickness of mats and the flame retardancy was observed. 


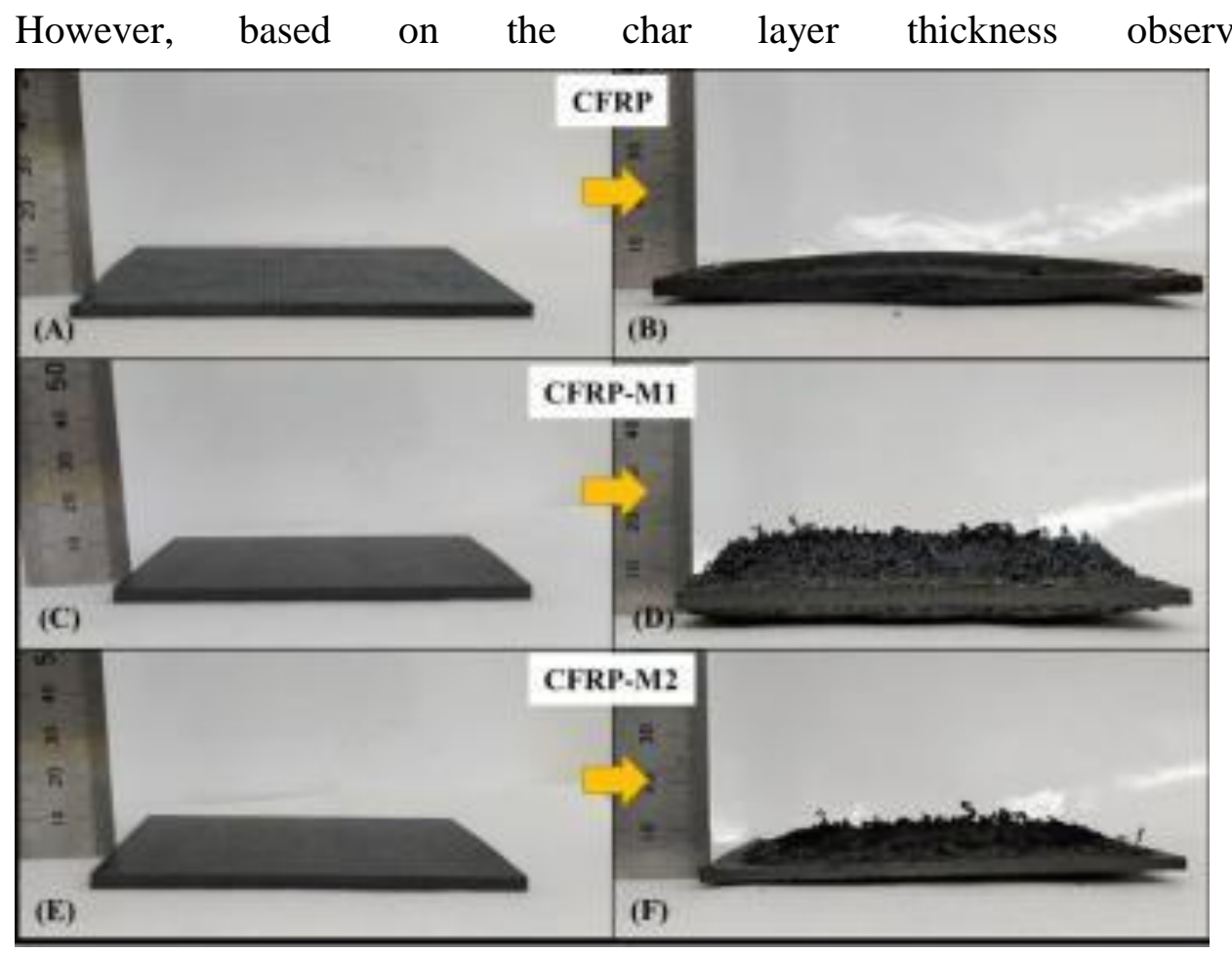

Figure 4, and the areal weight of mats, it was predicted that more expandable graphite in the M1 mat resulted in a higher char depth when composite was exposed to the heat flux. On the other hand, the residual char was not able to dictate fire performance alone, the inorganic fibres such as mineral fibre $(\sim 0.03 \mathrm{~W} / \mathrm{m} \mathrm{K})$ and glass fibre $(0.04 \sim 0.05 \mathrm{~W} / \mathrm{m} \mathrm{K})$ with low thermal conductivity also played a role as thermal insulate barrier supporting the heat resistance ${ }^{32-34}$. As can be seen from Table 1, it was observed that more than $20 \%$ mineral fibre with lower thermal conductivity was mixed in the M1 mat which could show better thermal insulation performance than M2 mat.

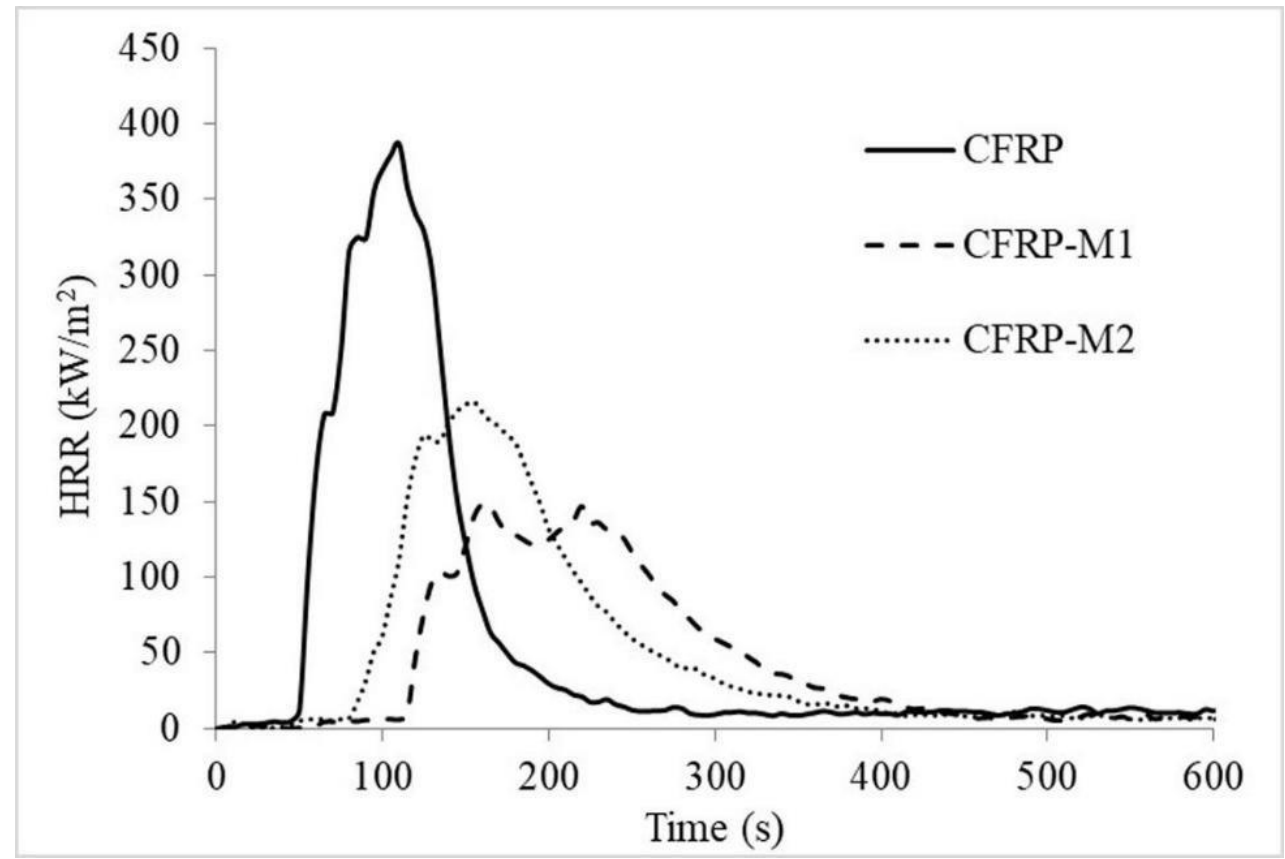


Figure 3 showed the HRR variation as a function of time for the composite samples with the intumescent mats (CFRP-M1 and CFRP-M2) and control group (CFRP). The CFRP showed three peaks spun over $300 \mathrm{~s}$, the sudden rise in HRR curve after ignition might be attributed to the initiation of the burning process, the sudden increase in the amount of combustible volatiles from heat-induced depolymerisation led to a rapid release of heat, after which a slight reduction in the HRR was probably due to the formation of a char layer on the top surface. The continuous combustion process with exposure to high radiant heat flux caused an increase of the temperature along the depth of laminate leading to the oxidation of char and further heat transfer through the laminate that gave rise to a second peak (the max value). After exposure times of $110 \mathrm{~s}$, with the depletion in the volume of combustible material, the HRR started to decrease inescapably.

Table 3: Cone calorimetric data for the composite at $50 \mathrm{KW} / \mathrm{m}^{2}$ heat fluxes with an ignition source.

\begin{tabular}{|c|c|c|c|c|}
\hline $\begin{array}{c}\text { Sample } \\
\text { codes }\end{array}$ & TTI & $\begin{array}{c}\text { PHRR } \\
(\mathrm{s})\end{array}$ & $\begin{array}{c}\text { TPHRR } \\
\left(\mathrm{KW} / \mathrm{m}^{2}\right)\end{array}$ & $\begin{array}{c}\text { THR } \\
(\mathrm{s})\end{array}$ \\
\hline CFRP & 45 & 381 & 115 & 43 \\
\hline CFRP-M1 & 109 & 148 & 188 & 29 \\
\hline CFRP-M2 & 91 & 231 & 165 & 33 \\
\hline
\end{tabular}

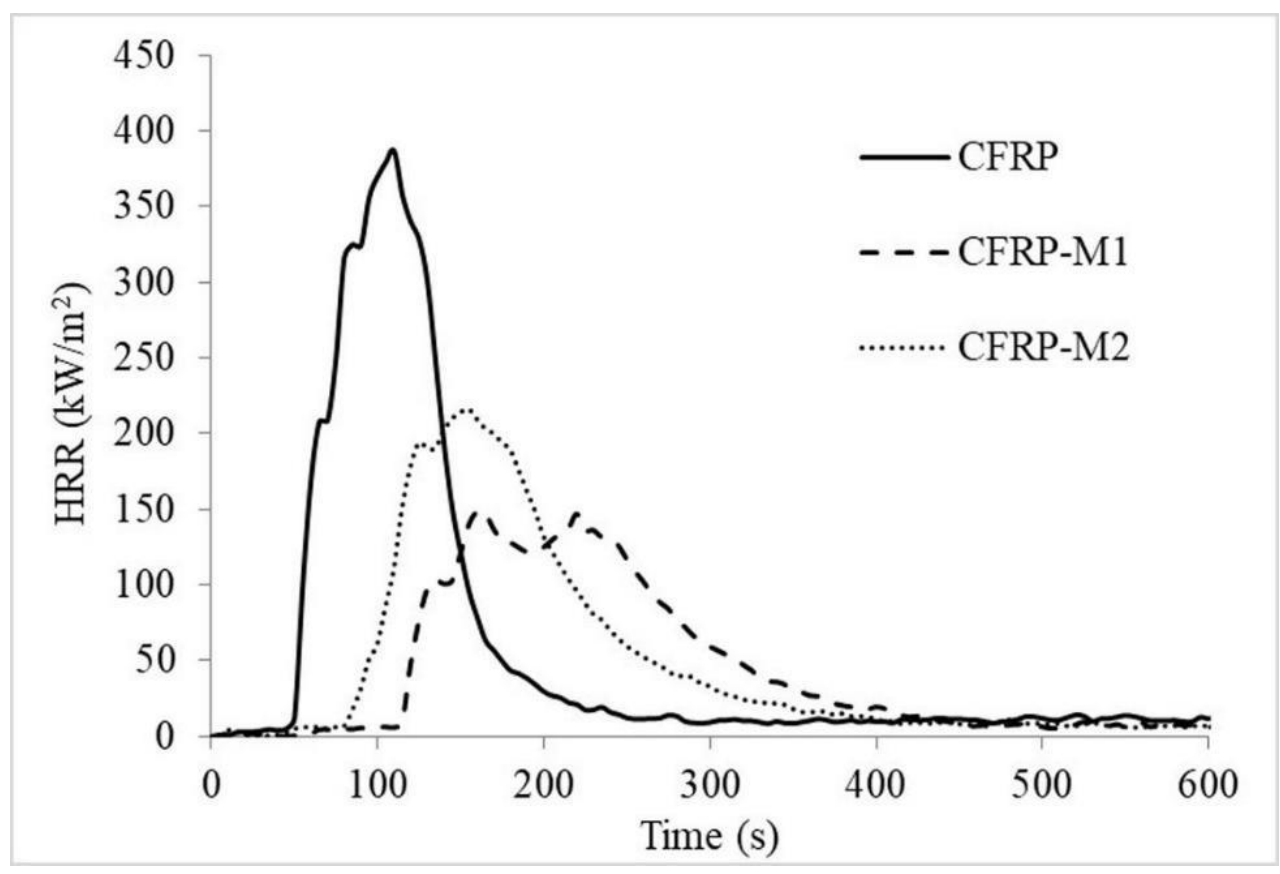


Figure 3: Curves of heat release rate versus time of the composite samples at 50 $\mathrm{KW} / \mathrm{m}^{2}$ heat fluxes with an ignition source.

The general shape of CFRP-M2 in HRR curve was similar to the CFRP, whilst the highest peak of HRR curve was the value of $231 \mathrm{~kW} / \mathrm{m}^{2}$. The intumescent mat with expandable graphite acted as a thermal barrier and a physical protective layer; the carbonised char layer was able to prevent the diffusion of heat and oxygen to the pyrolysis zone. As such, the rate of heat transfer perpendicular to the exposed surface was significantly reduced. Kandare et a.l ${ }^{31}$ had confirmed this phenomenological event and suggested that may result in the delayed commencement of combustion process which meant the time to ignite.

Compared with HRR curve of CFRP-M2, the CFRP-M1 composite presented better flame retardancy. A sudden rise of HRR was given at $109 \mathrm{~s}$, and then the peak with max value of $148 \mathrm{~kW} / \mathrm{m}^{2}$ was reached. Due to the formation of the thicker expanded char layer on the top surface, the rate of heat transfer along the composite laminate was abated significantly so that the PHRR value of CFRP-M1 was much lower than CFRP and CFRP-M2. Furthermore, a steady-state flaming process ensued, and a rise to the other peak of $146 \mathrm{~kW} / \mathrm{m}^{2}$ was observed at exposure times of $220 \mathrm{~s}$. Beyond the exposure time of $220 \mathrm{~s}$, the HRR decreased with the depletion of combustible material.

The THR values were obtained from the integration of the HRR-time curves from the

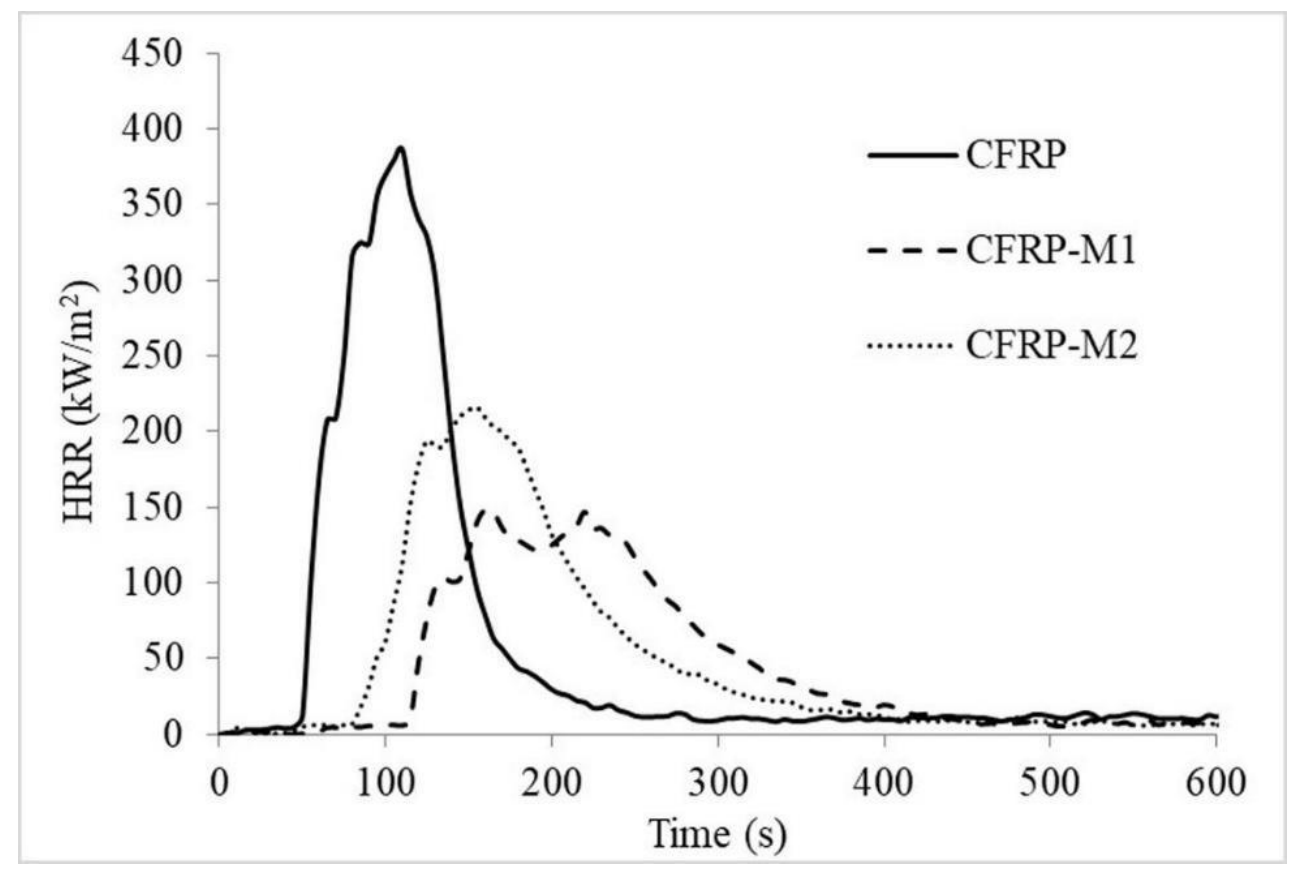

Figure 3 and recorded in the Table 3. The values of $29 \mathrm{MJ} / \mathrm{m}^{2}$ and $33 \mathrm{MJ} / \mathrm{m}^{2}$ were observed for CFRP-M1 and CFRP-M2, respectively, but much lower than that of CFRP with value of $43 \mathrm{MJ} / \mathrm{m}^{2}$. Kandare et al. ${ }^{21}$ reported similar results and found that the 
intumescent mat only acted as passive protection, delaying and slowing down the burning process under the heat or fire.

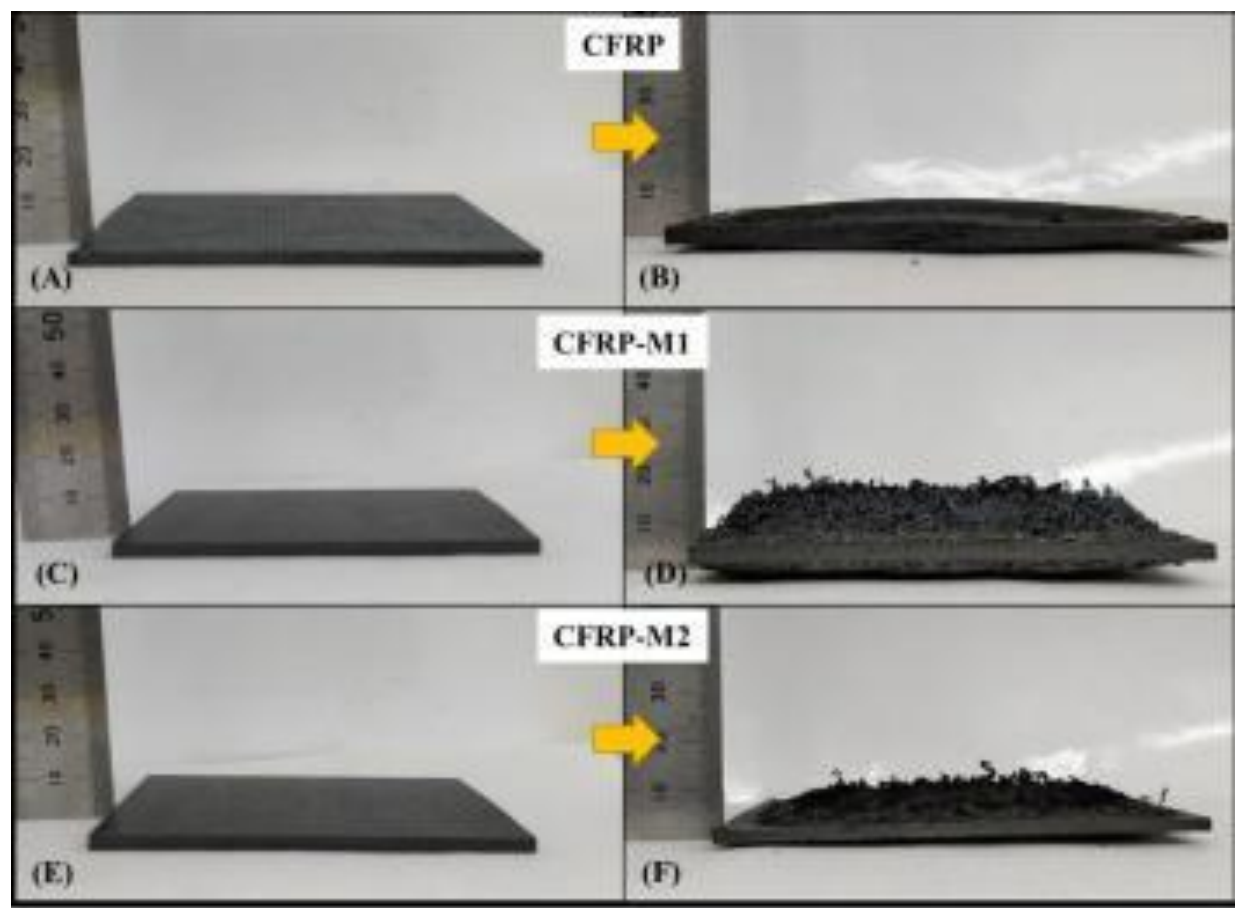

Figure 4: The digital images of samples before (A, C, E) and after exposure of composites (B, D, F) to a 50kW/m2 heat flux for $600 \mathrm{~s}$.

\section{Flexural properties of composites before exposure to fire}

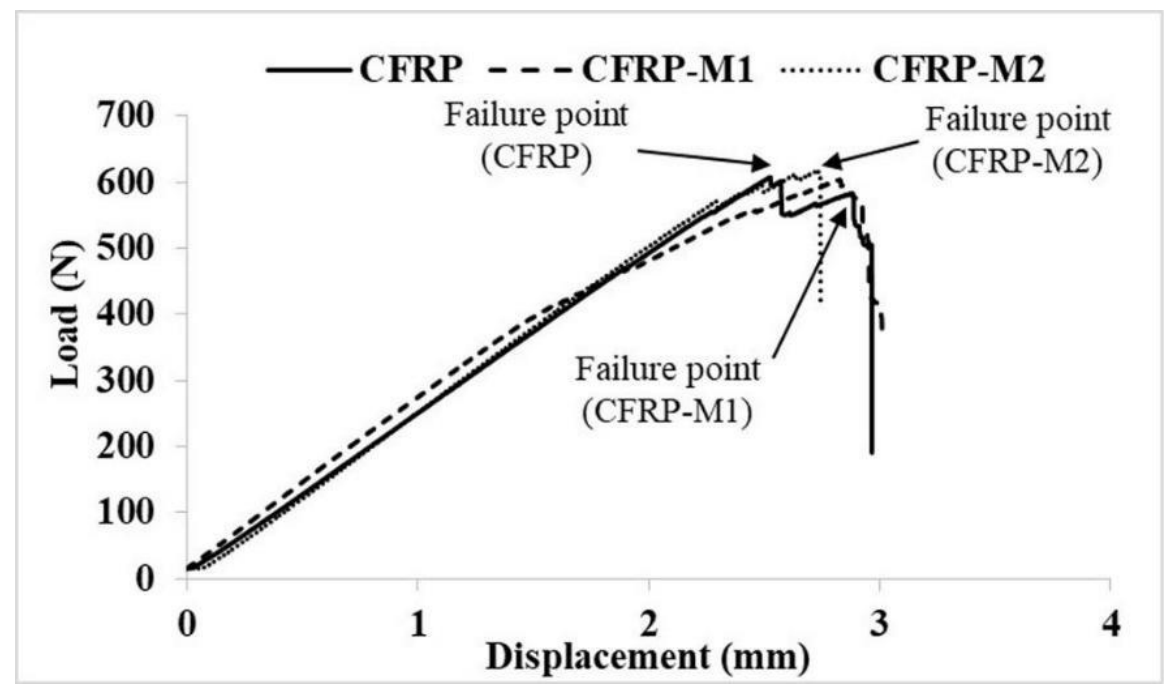

Figure 5 illustrated the load-displacement plot for laminate flame retardant composite in this study. It was clear that all composites were failed in a sudden brittle fracture 
finally, and the peak value of load for CFRP composite was close to the composite with mats M1 and M2.

However, as seen in Figure 6, the M1 mat covering the core composite reduced the flexural strength and modulus from $541 \pm 45 \mathrm{MPa}$ and $33 \pm 1 \mathrm{GPa}$ to $455 \pm 44 \mathrm{MPa}$ and $28 \pm 2 \mathrm{GPa}$, respectively, whilst the composite with M2 mat showed $519 \pm 31 \mathrm{MPa}$ and $29 \pm 2 \mathrm{GPa}$ for flexural strength and modulus.

According to the composite specification recorded in Table 2, the composite thickness was increased from $3 \mathrm{~mm}$ to $3.25 \mathrm{~mm}$ and $3.14 \mathrm{~mm}$ for CFRP-M1 and CFRP-M2, respectively. Based on the equation 1 and 2, with the consistent flexural load, the flexural strength and modulus would be affected by the variation of composite thickness. On the other hand, as the intumescent mats (M1 and M2) were dry mat without resin, the mats in compression moulding process would suck resin from prepreg to impregnate themselves, so that the volume of resin in the core parts which demonstrate the mechanical performance was decreased, and the mechanical properties of composite were reduced consequently.

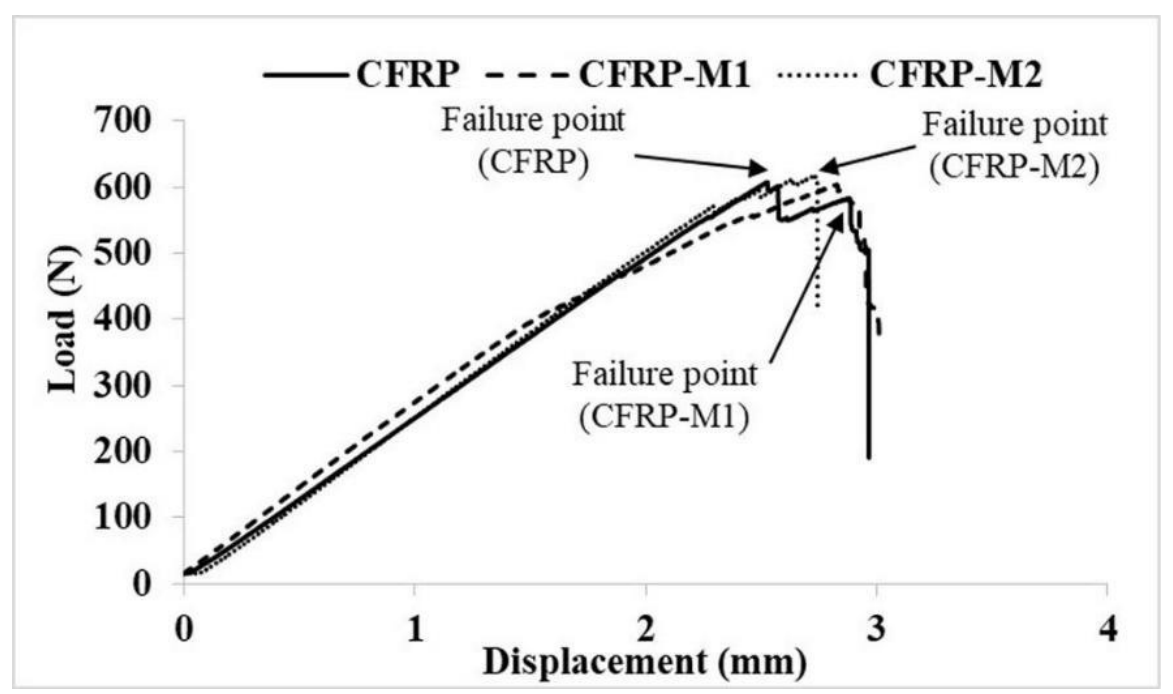

Figure 5: The flexural properties test plot of load vs displacement of composites. 


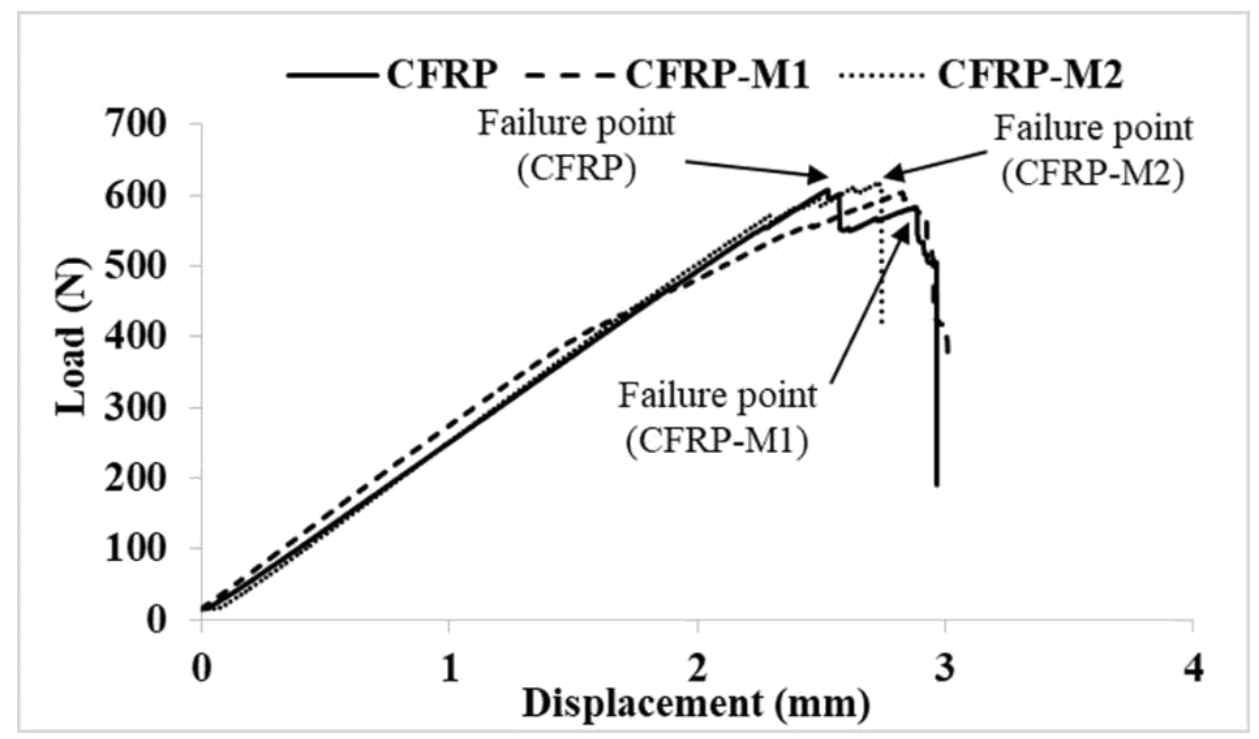

Figure 6: The flexural strength and flexural modulus of composites before burning at $50 \mathrm{KW} / \mathrm{m}^{2}$ heat fluxes with an ignition source.

\section{Post-fire performance of composite}

The flexural strength and modulus measured from the composite under the heat flux of

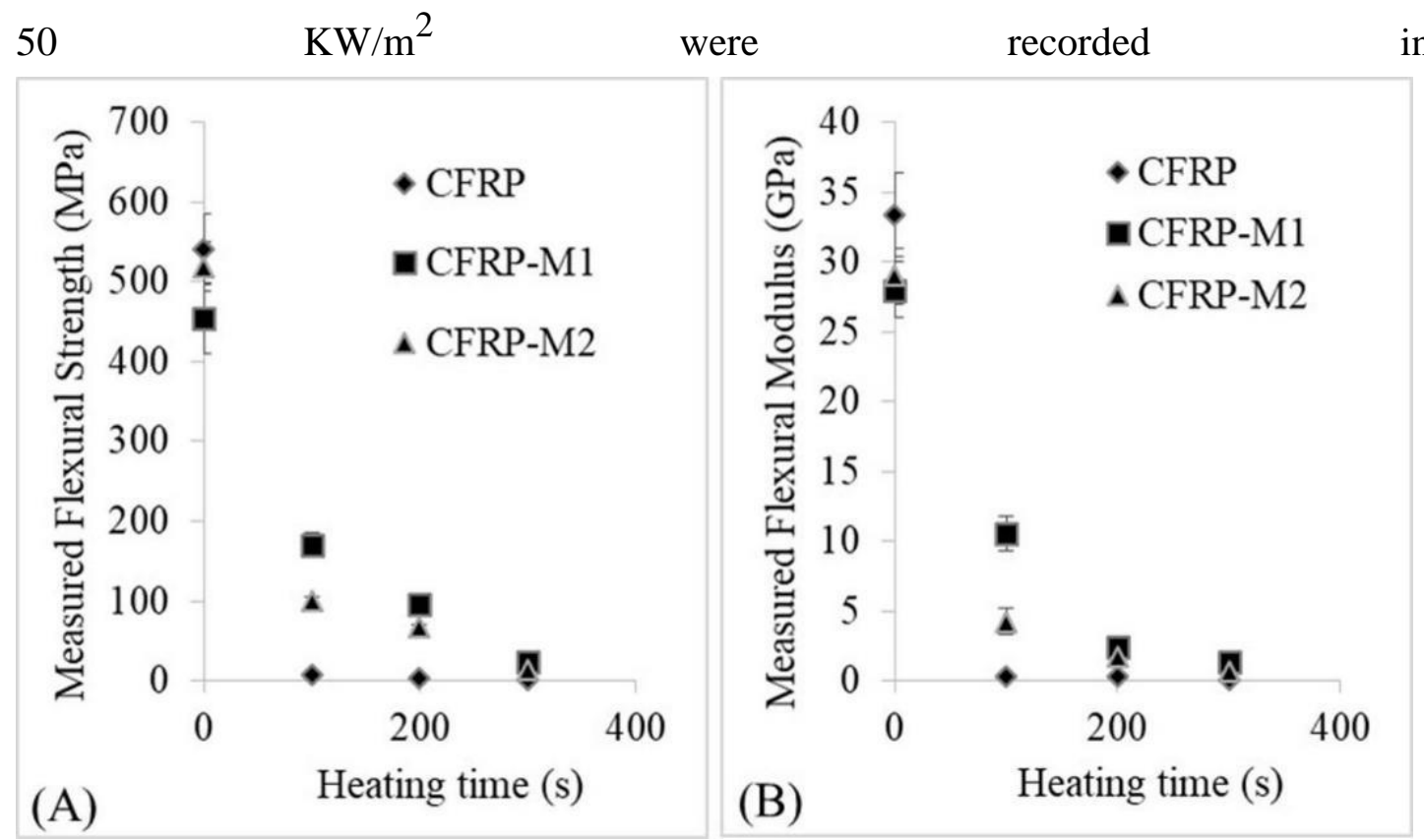

Figure 7. Compared with CFRP control group, CFRP-M1 and CFRP-M2 presented better retention of flexural performance under the heat flux. M1 mat could improve the retention of flexural strength and modulus, where the $63 \%$ and $64 \%$ reduction were observed at $100 \mathrm{~s}$, respectively. However, the flexural strength and modulus of CFRP-M2 were reduced by $81 \%$ and $86 \%$ at 100 s, respectively. 


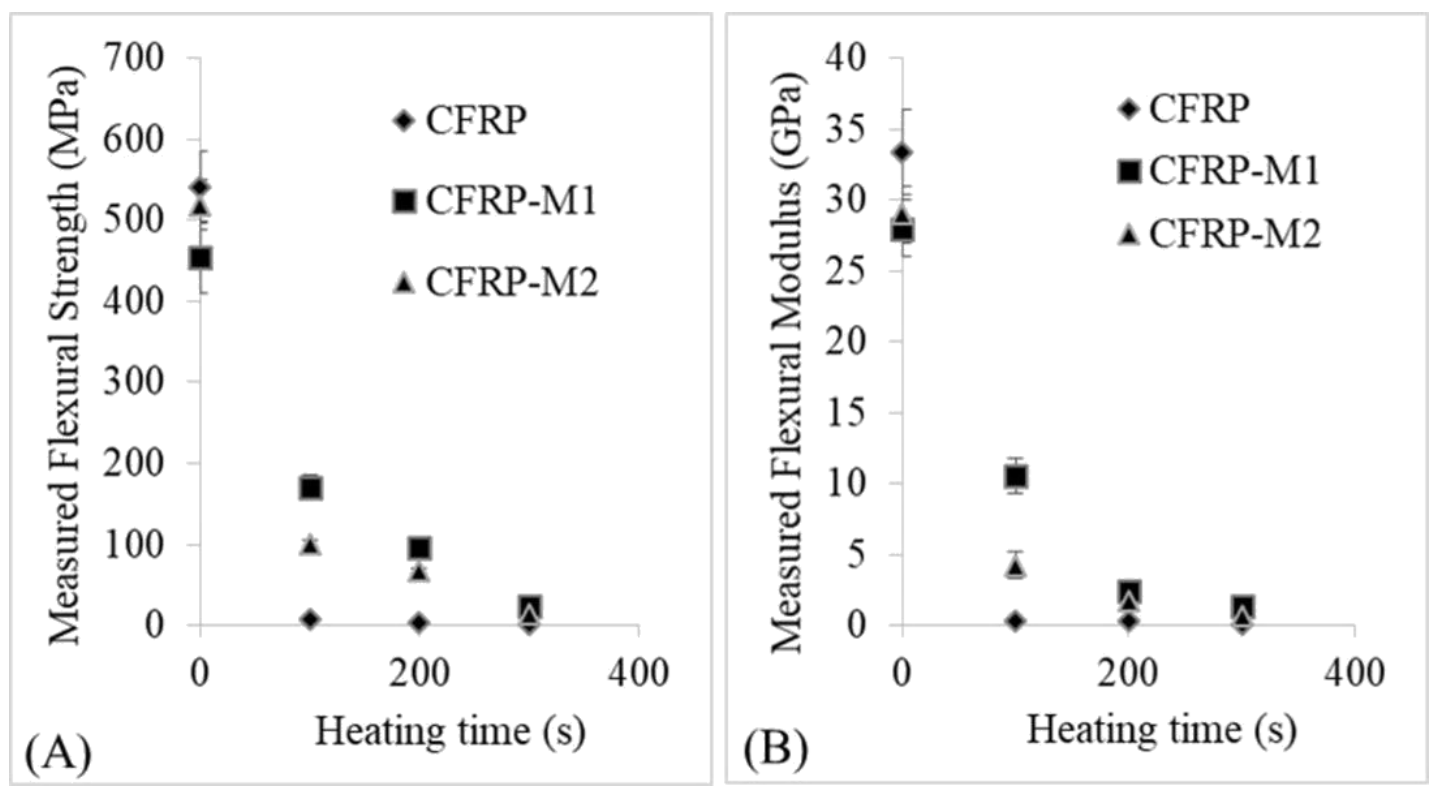

Figure 7: Effect of heating time on the post-fire flexural strength (A) and flexural modulus (B) of composites with $50 \mathrm{KW} / \mathrm{m}^{2}$ heat fluxes. The error bars represent two standard deviations in the measured post-fire properties.

The microscopy and SEM images were recorded in

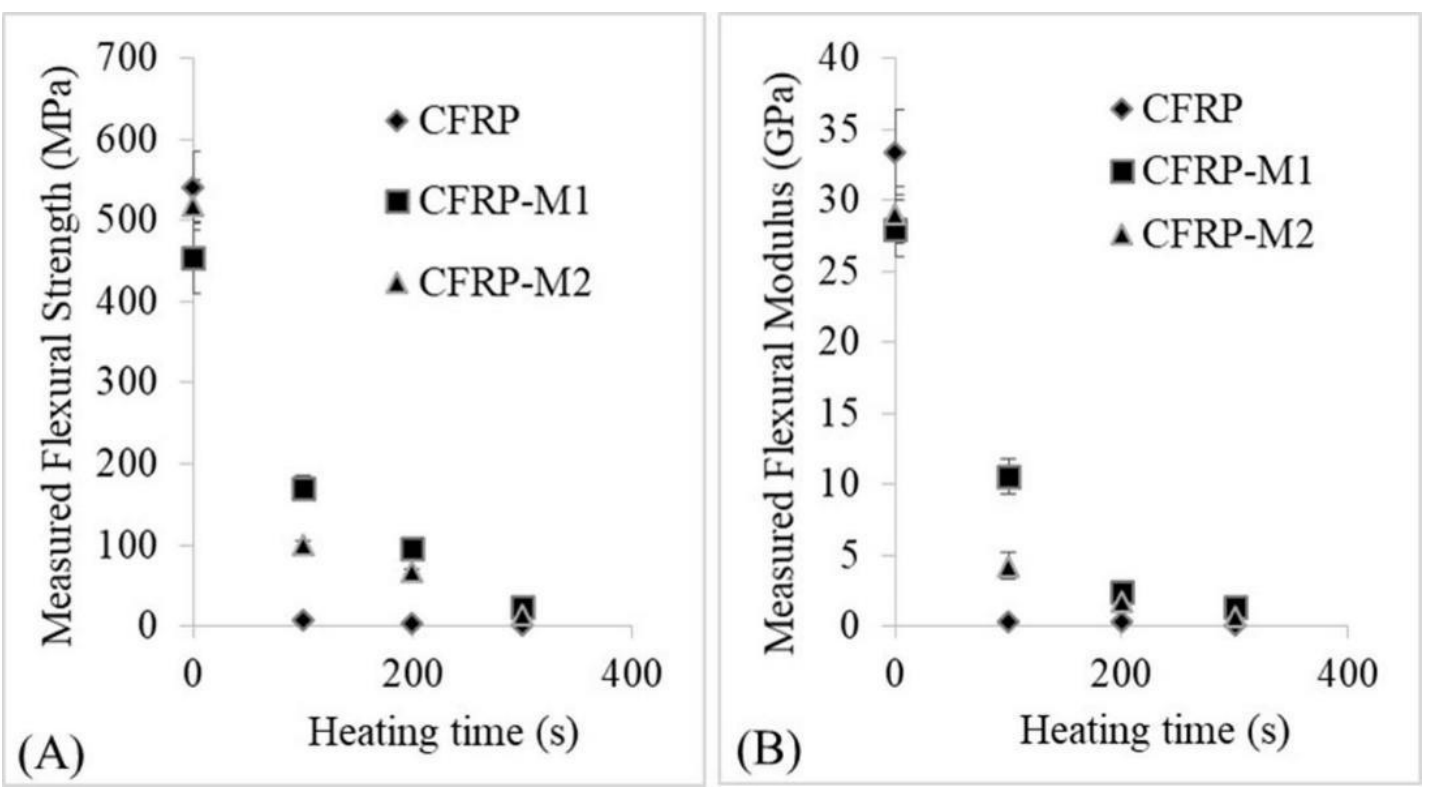




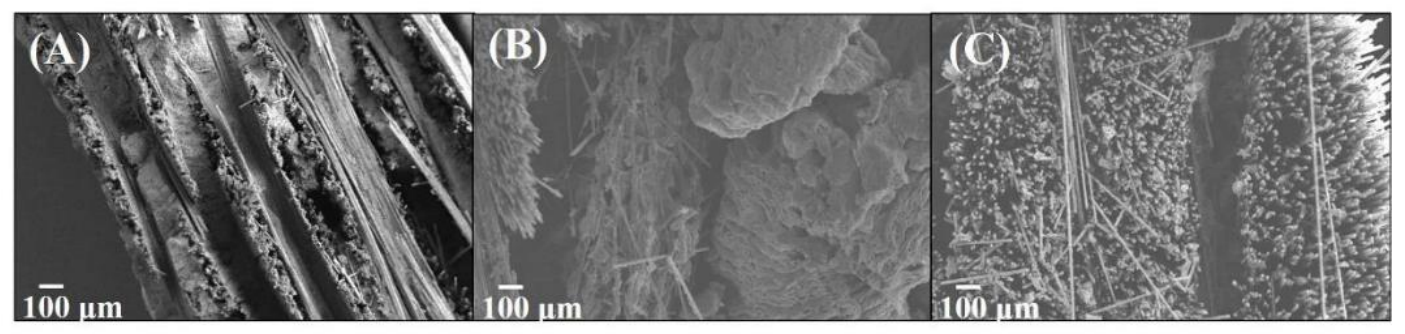

Figure 9. The variation of thickness for intumescent mat exposed to heat and the unburnt layer of composite during the heating process were recorded in the

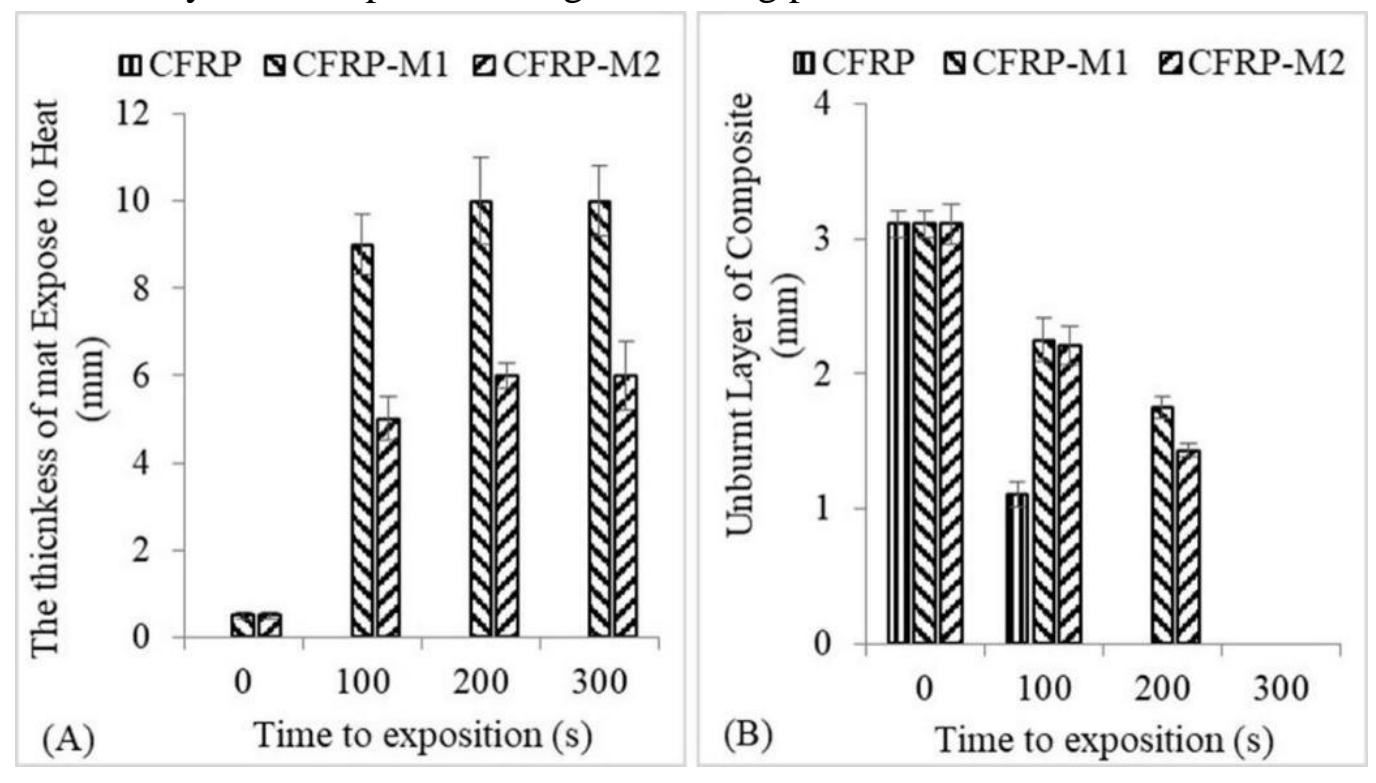

Figure 10. Many studies

$27,28,30,35$

mechanical properties of composites was caused by the fire, particularly the polymer matrix damage. When the composites were exposed to a heat source or fire, the polymer matrix underwent the thermal decomposition leading to the depletion of its mechanical properties such as strength and modulus, and the reduction in mechanical properties was usually observed above the glass transition temperature of the polymer.

With the burning of composite when exposed to fire, the resin matrix was decomposed and burnt off, resulting in the exposure of fibres and reduction of mechanical performance. Following the cross-section view of composite at different time points of heating period 

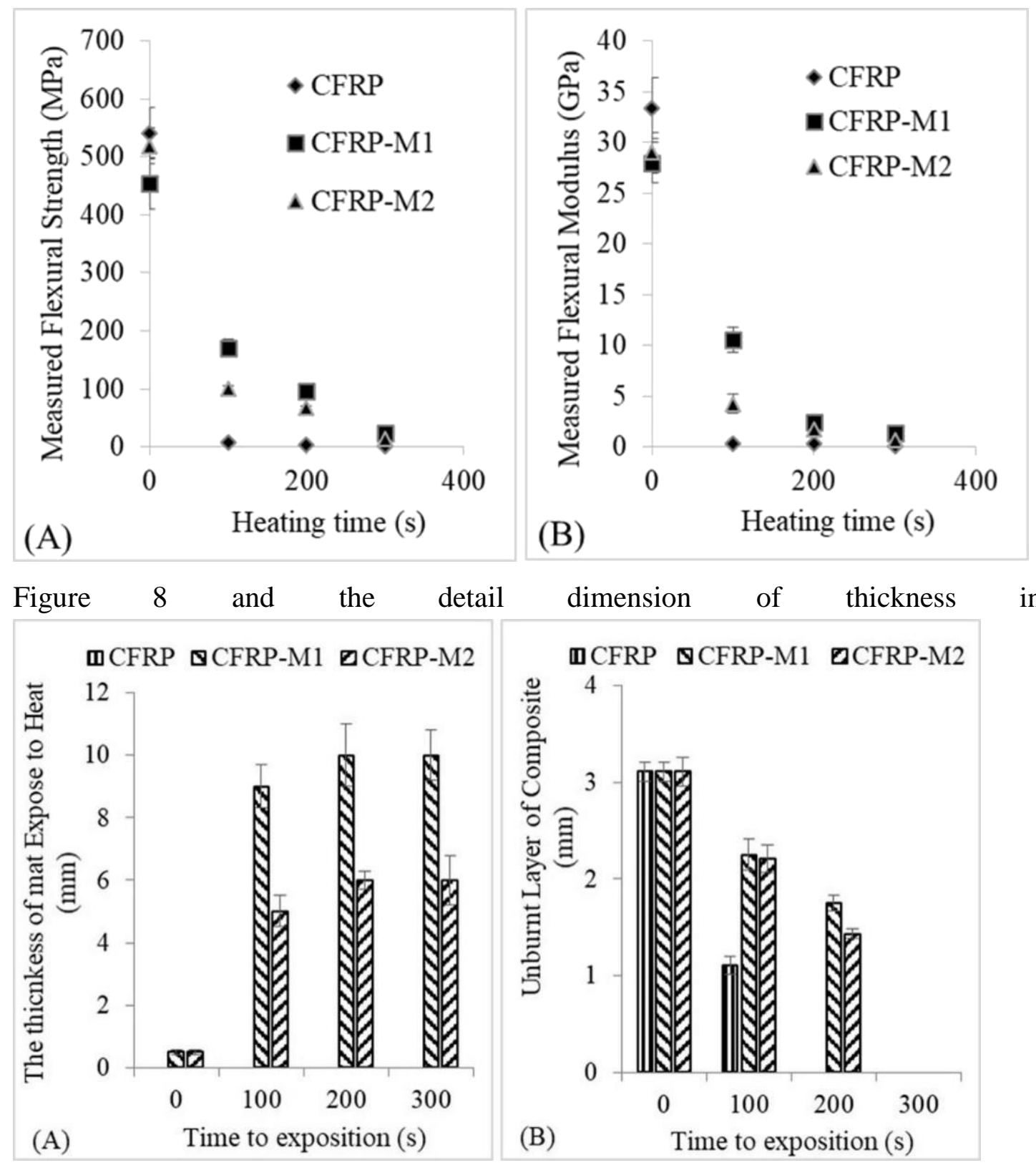

Figure 10, the CFRP composite without mats protection was burnt significantly in $100 \mathrm{~s}$ and the residual unburnt layer was burnt off at $200 \mathrm{~s}$. However, the unburnt layer of CFRP-M1 and CFRP-M2 composite were reduced from $3.25 \mathrm{~mm}$ and $3.14 \mathrm{~mm}$ to 
$1.75 \mathrm{~mm}$ and $1.43 \mathrm{~mm}$ at $\begin{array}{r}200 \quad \mathrm{~s} \text { with } \\ \text { respectively. Compared }\end{array}$

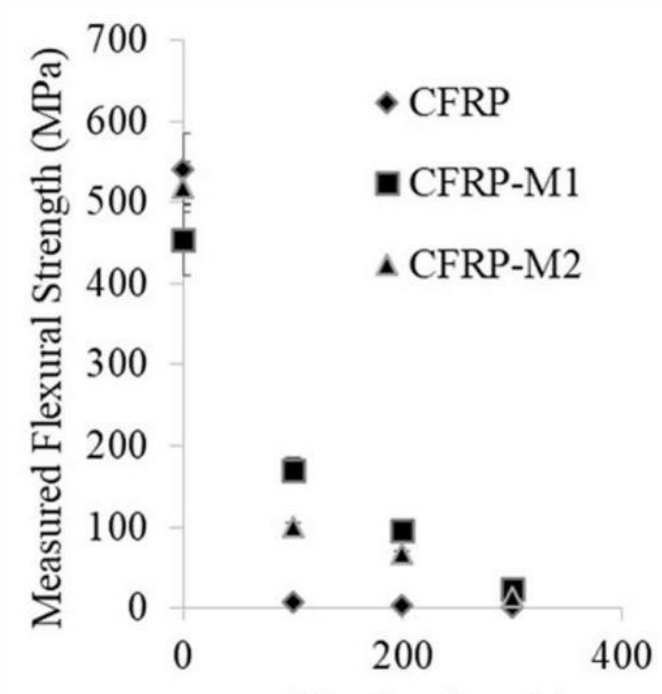

(A)

Heating time (s)

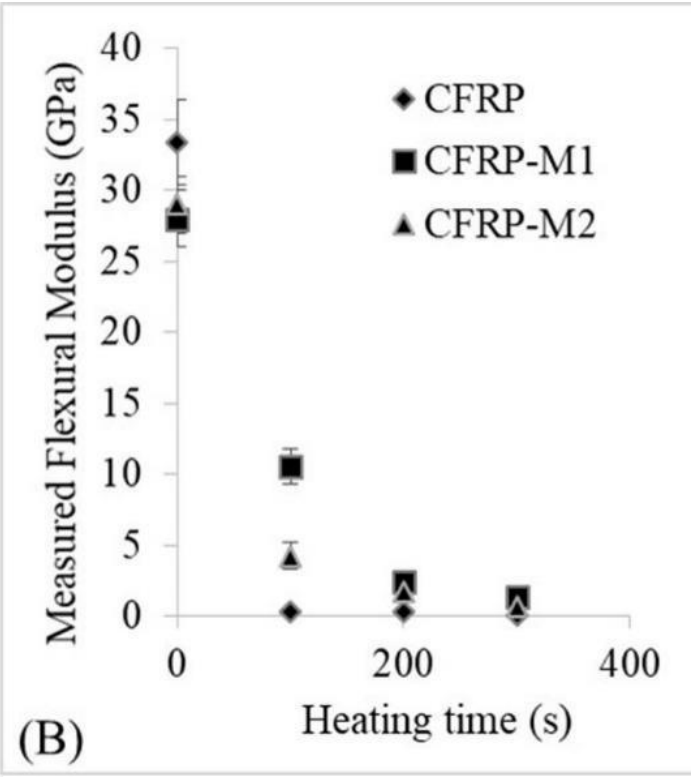

Figure 7, it could be summarised that the more extended period of burning, the thicker burnt layer and lower mechanical performance of composite. Furthermore, according

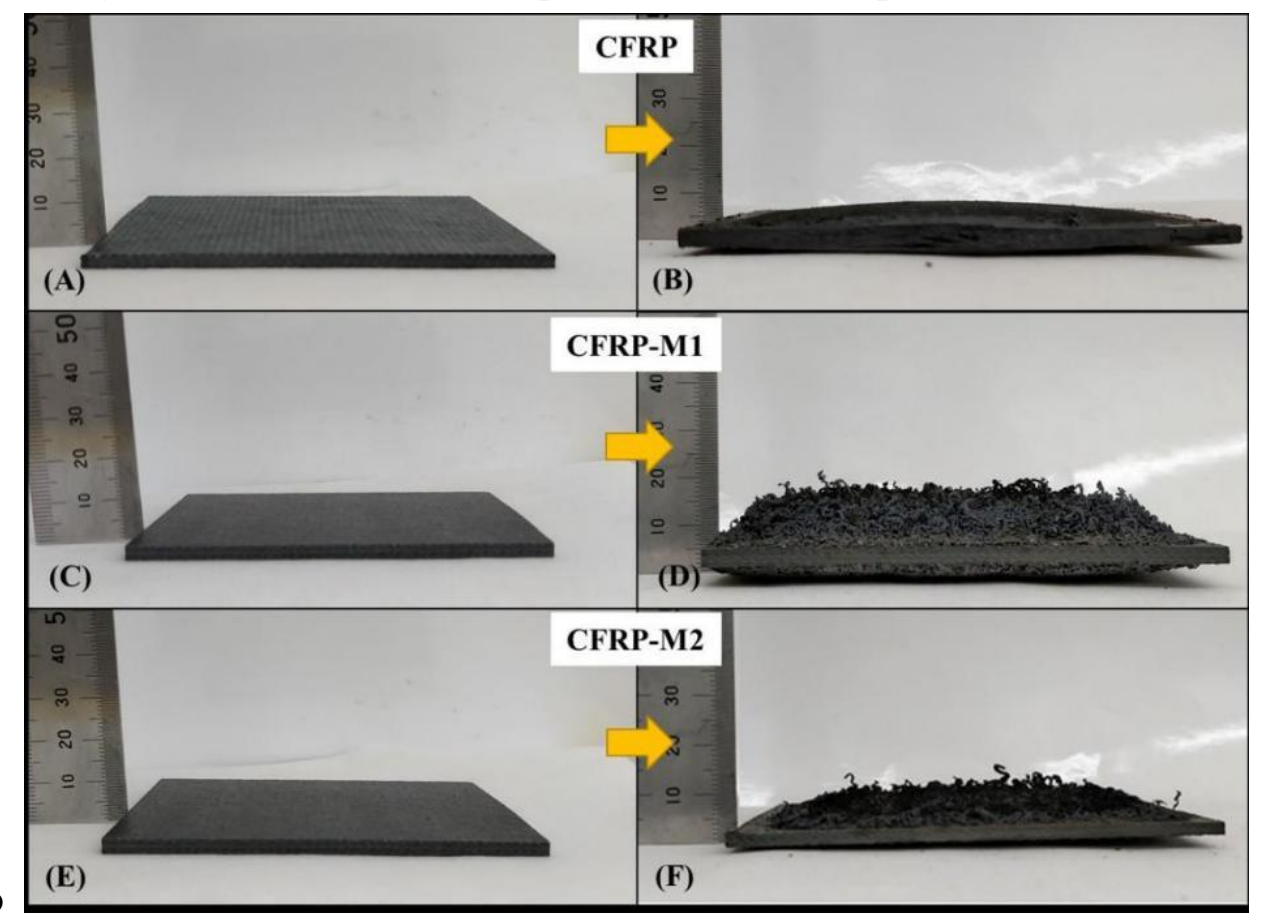


Figure

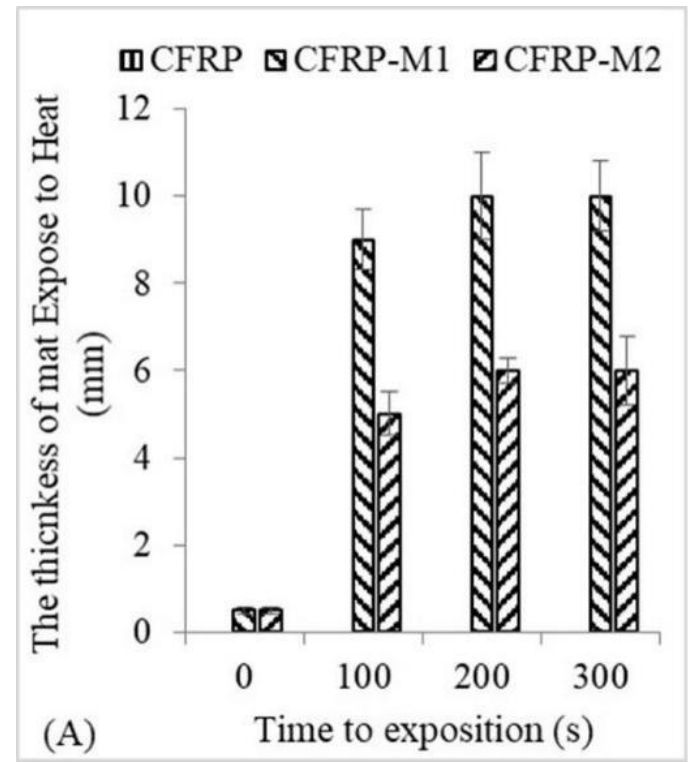

and

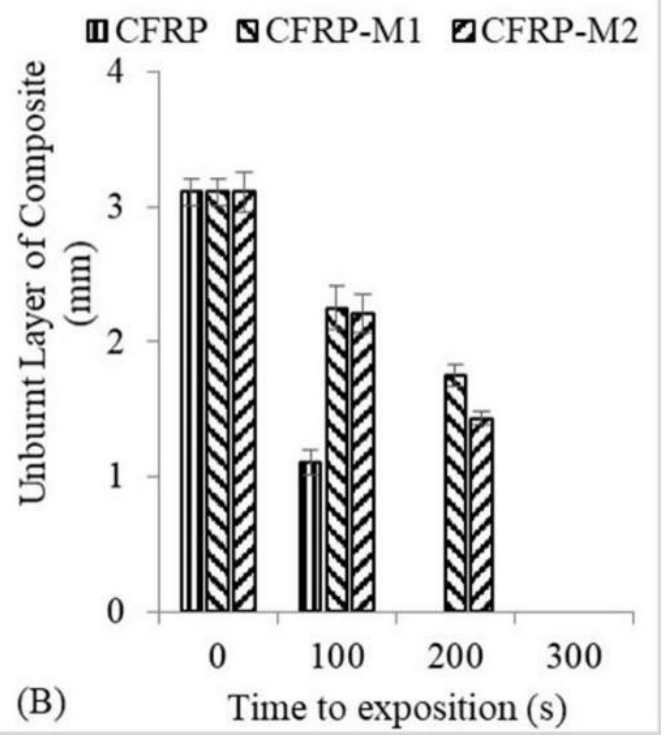

Figure 10, the CFRP-M1 and CFRP-M2 with the mat protection showed the thick expanded graphite layer which was $10 \mathrm{~mm}$ and $5 \mathrm{~mm}$ by $300 \mathrm{~s}$, respectively. As such, the better post-fire performance for CFRP-M1 could be confirmed due to the thicker expanded graphite formed on the mat surface which protected composites with better thermal insulation and flame retardant performance. However, as the structure of intumescent mats with expanded graphite after burning were shrunk when cool to room temperature, the expanded mats of CFRP-M1 and CFRP-M2 were observed to be thin $\begin{array}{llllll}\text { with the } & & 2 & \mathrm{~mm} & \text { in }\end{array}$
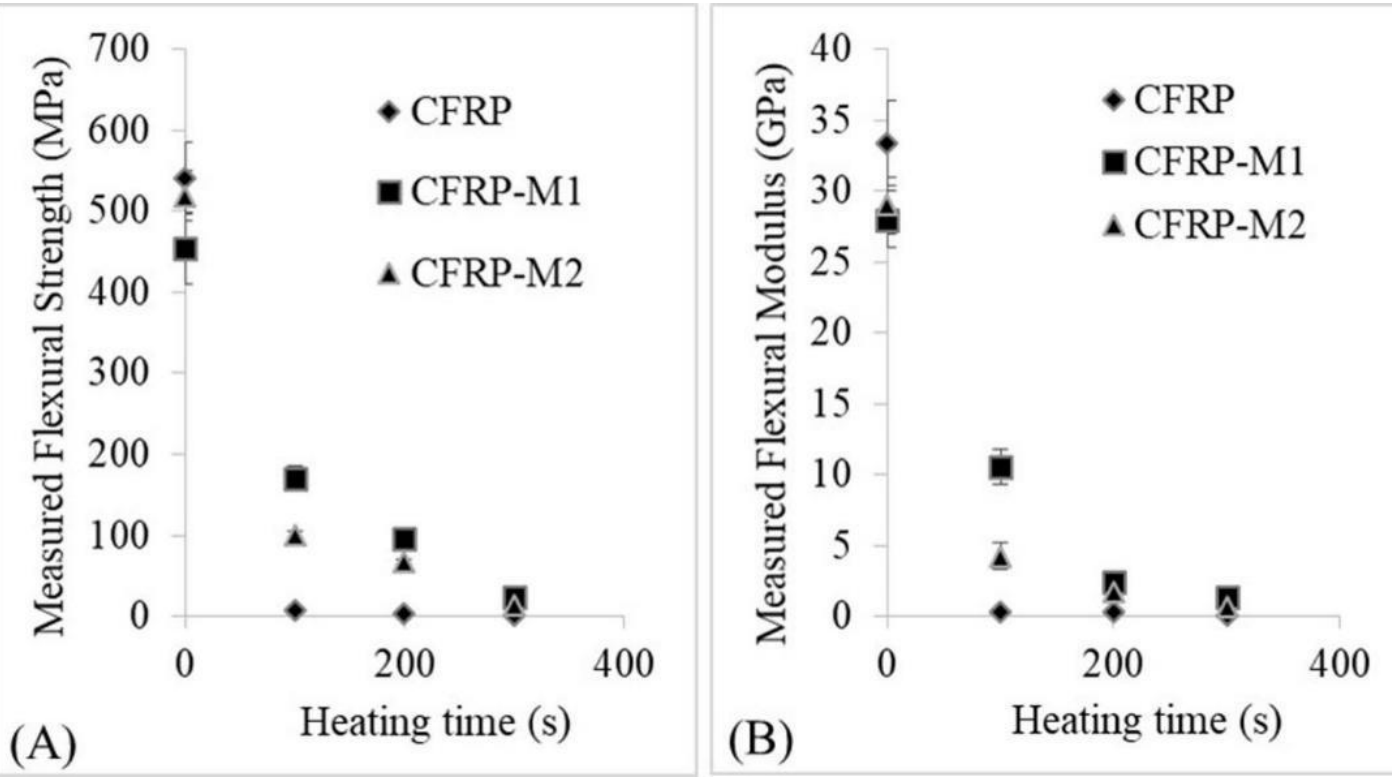

Figure 8 . By the time point of $300 \mathrm{~s}$, all composites were seen to be fully burnt off, so that the flexural strength and modulus of all composite were observed to be zero by the $300 \mathrm{~s}$ of the burning period. 


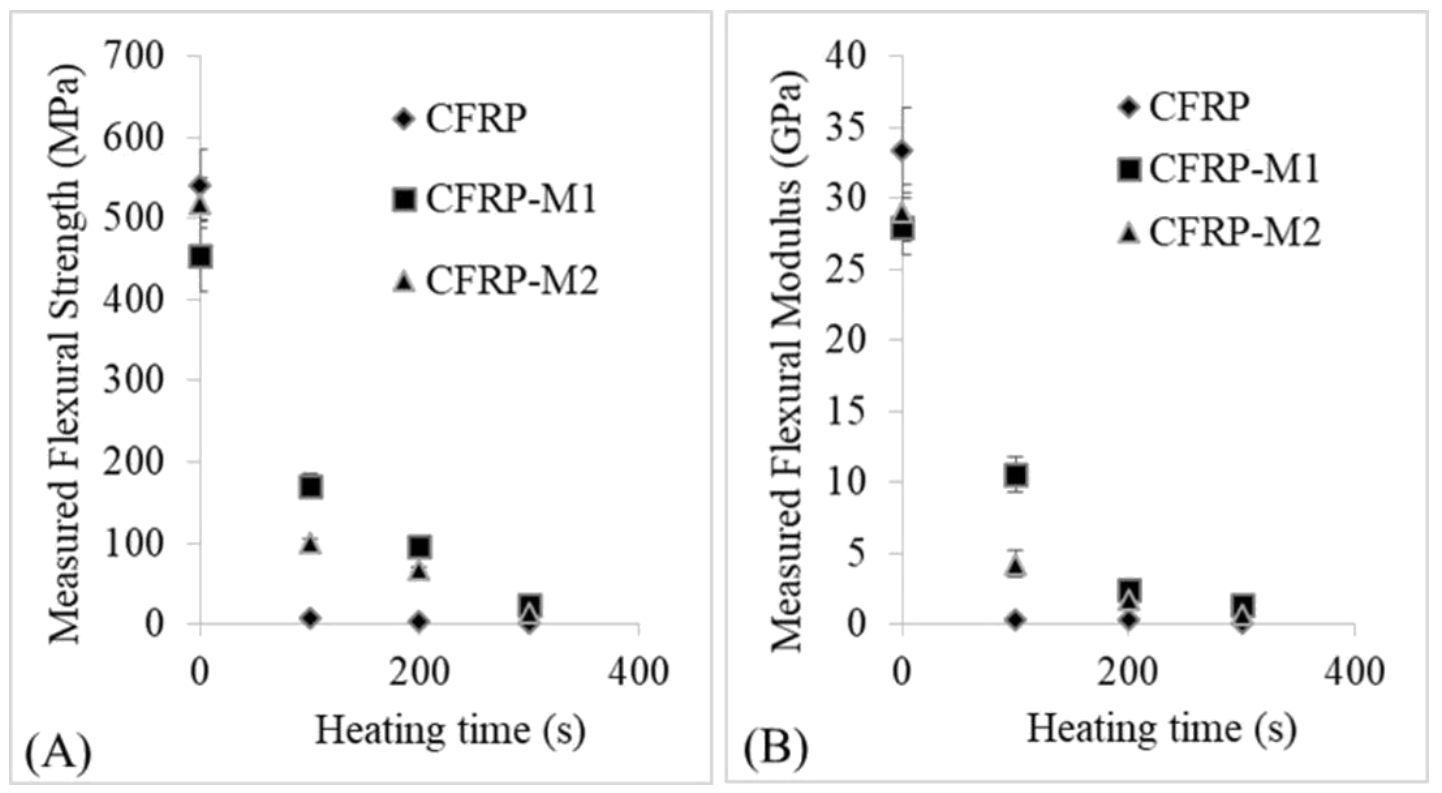

Figure 8: The cross-section view of fire damaged composites after $50 \mathrm{KW} / \mathrm{m}^{2}$ heat fluxes.

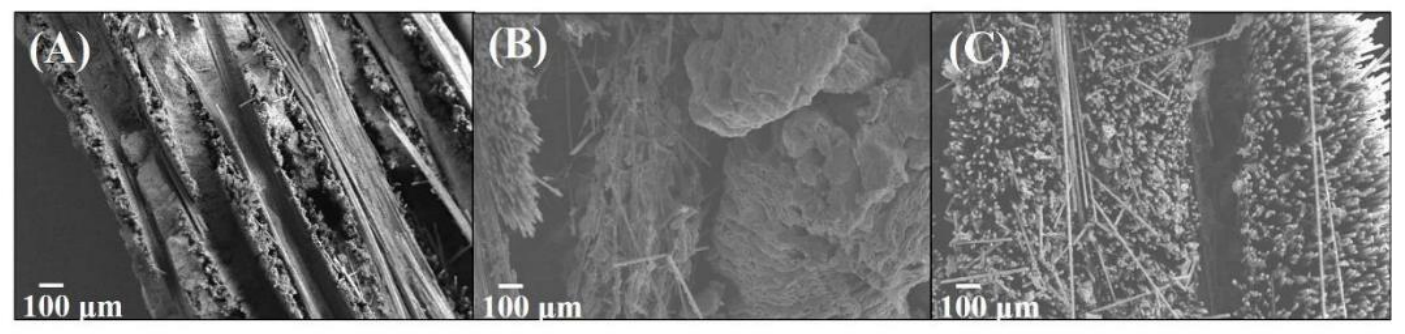

Figure 9: The SEM image of composite exposed to the fire at $50 \mathrm{KW} / \mathrm{m}^{2}$ heat fluxes, (A) unburnt layer, (B) Char, (C) burnt layer. 


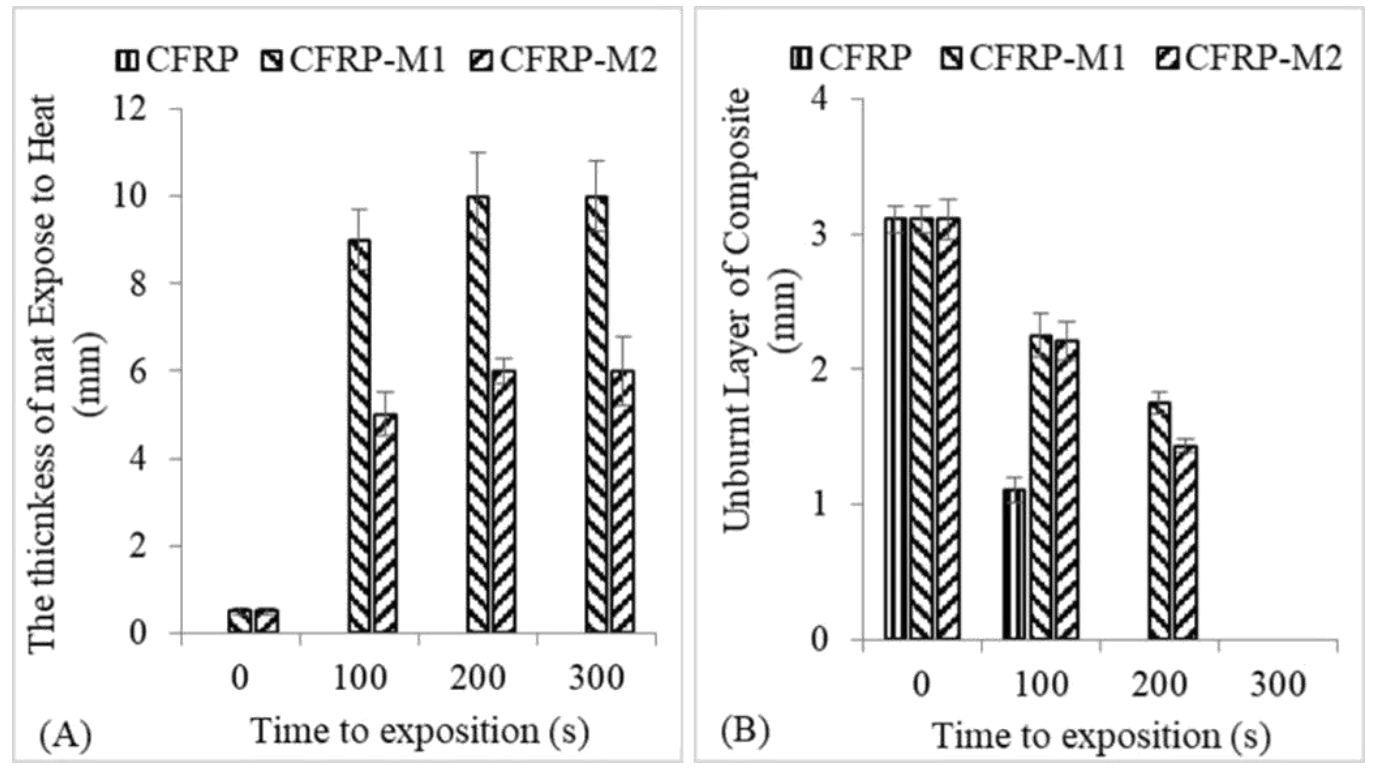

Figure 10: The thickness of (A) intumescent mat expose to fire at $50 \mathrm{KW} / \mathrm{m}^{2}$ heat fluxes and (B) unburnt layer of composites.

\section{Modelling of post-fire performance}

For the modelling of the composite properties under fire burning, the two-layer model is the most established analytical method for calculating the post-fire properties of laminates ${ }^{30}$. The model basically analyses the fire-damaged laminate as a two-layer structure with fully decomposed material and unburnt layer. To simplify the analysis, the mechanical properties of burnt layer are taken to be zero whilst the unburnt layer presented original performance in the determination of the theoretical post-fire properties. Based on the Equation (5-10), the original flexural strength, modulus and thickness of the unburnt layer for a given burning time would demonstrate the final post-fire flexural properties of composites.

As such, the flexural strength and modulus dropped rapidly when the burnt layer extended along the thickness of composite as the effective thickness for load bearing was reduced.

In this study, the thickness of the unburnt layer was determined visually using the optical microscopy during the observation of composite cross-section which was shown in 


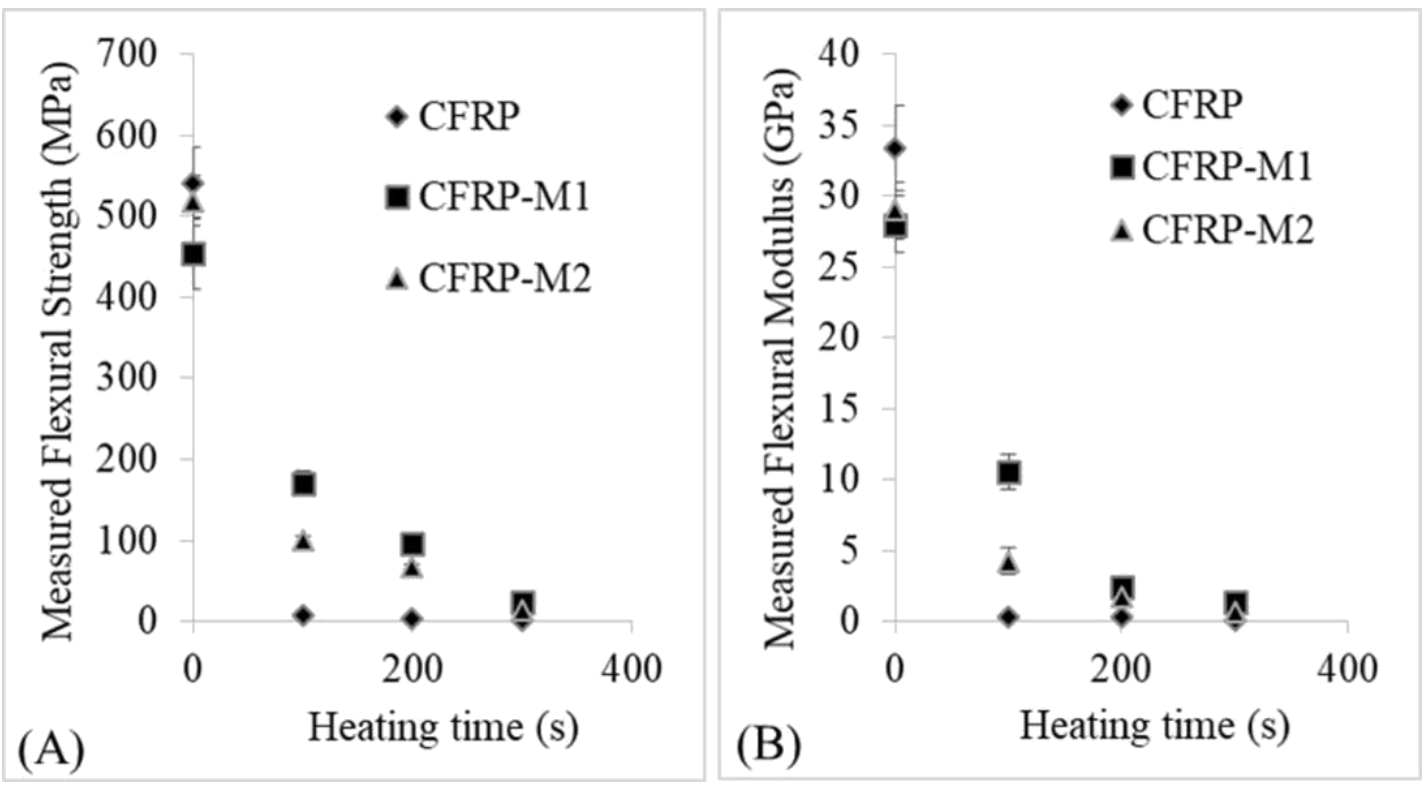

Figure 8, and a rapid decrease in the thickness of unburnt layer was shown with burning 

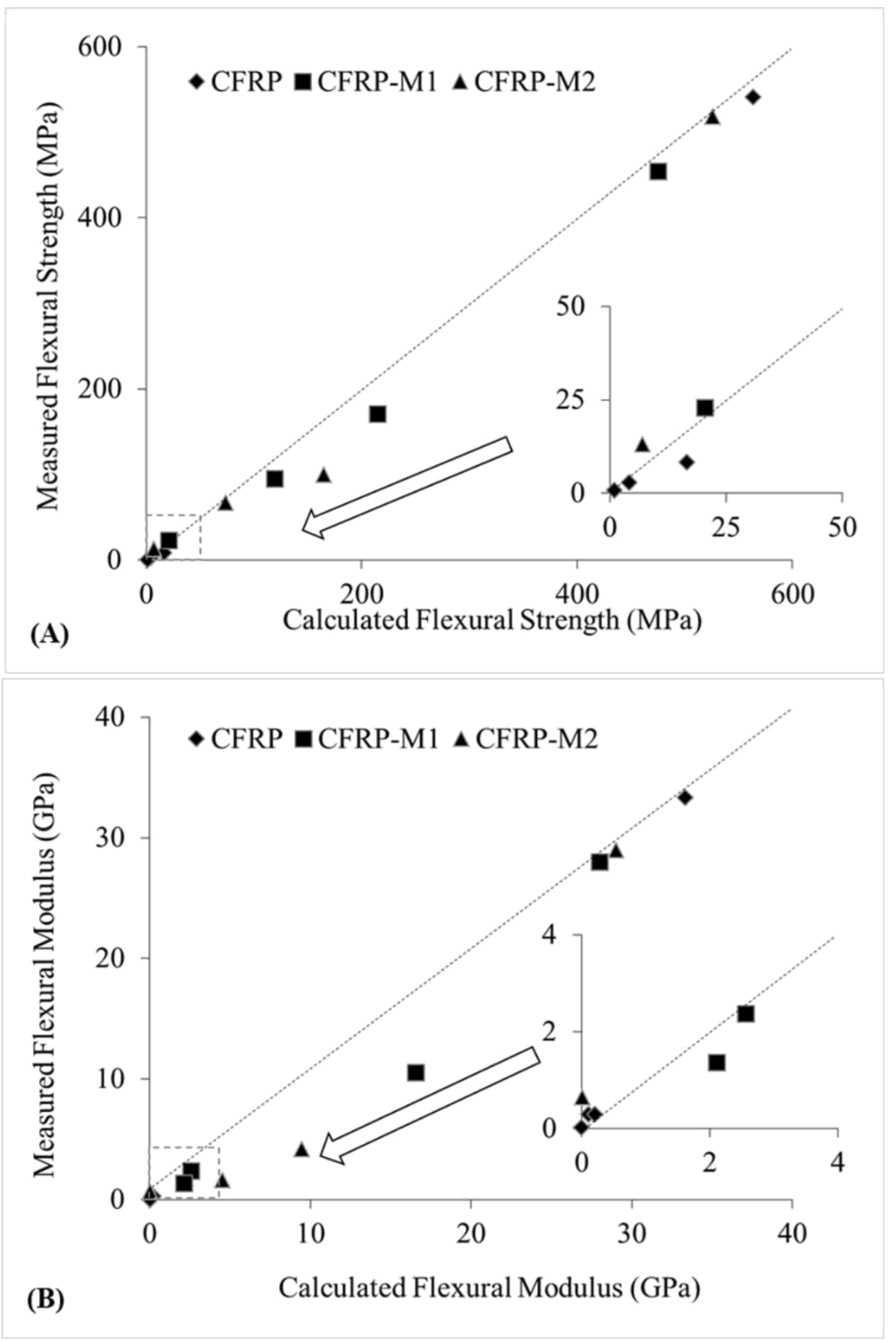

Figure 11 compared the theoretical values against the measured post-fire flexural modulus and strength values for all composite in this study. The straight line had a slope of unity, thus the closer the data points were to the line, the better the agreement 
between the theoretical properties and measured ones. The insets to the figures A \& B
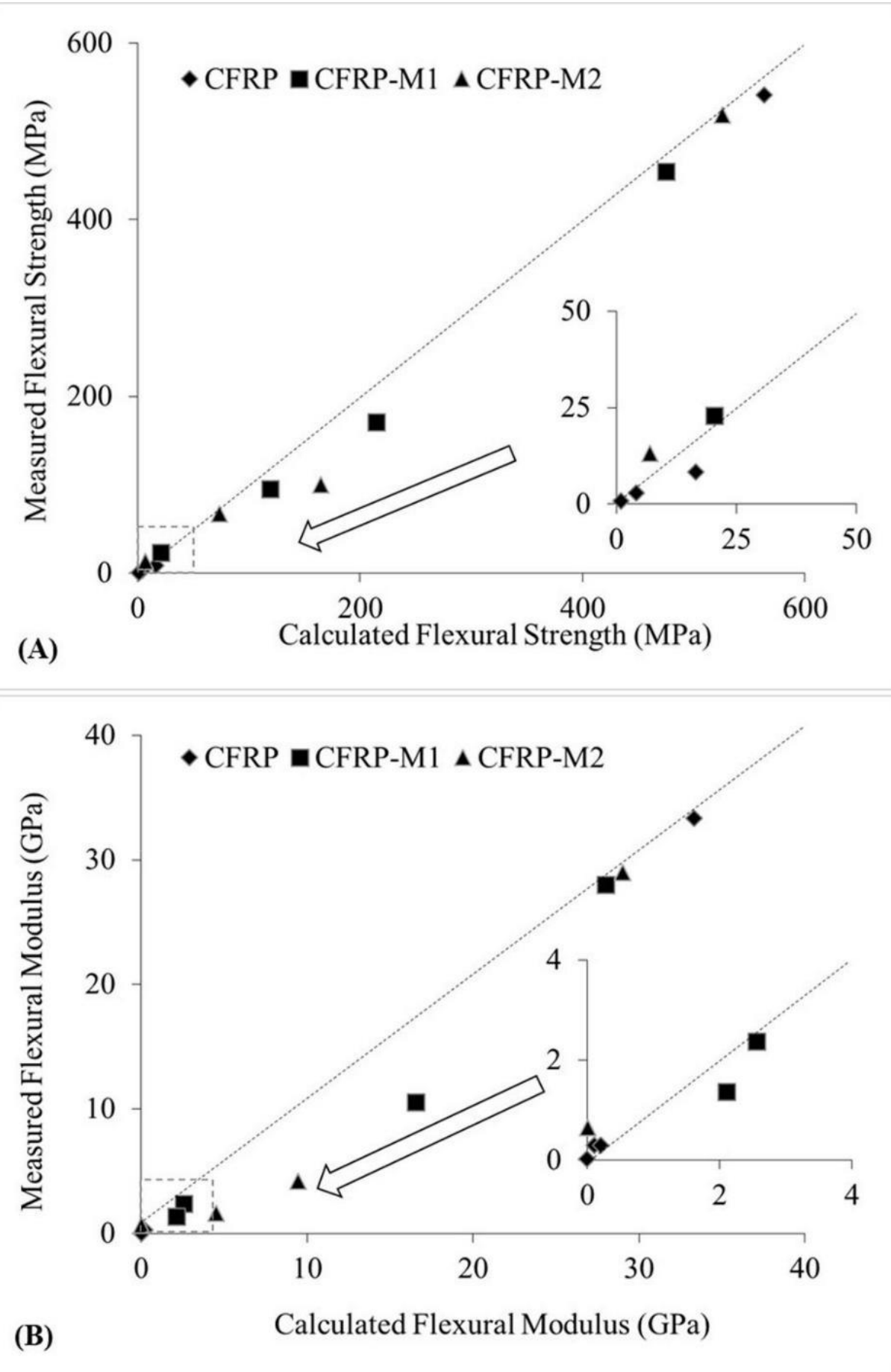

Figure 11 showed the cluster of the relatively low flexural properties in greater detail, and the most of the data points were observed close to the straight line, indicating a good agreement between theory and experiment. This revealed that the post-fire performance of composite with the intumescent mats can be accurately determined using the models which only required a few easily measured original mechanical parameters. 
However, some points were located in the section below the straight line, indicating the measured values of flexural properties lower than the theoretical ones. This difference could be attributed to the delamination in the unburnt layer resulting in the reduction of flexural properties. As the two-layer model ${ }^{30}$ in this study was the ideal structure of composite combined with bunt layer and the unburnt layer where the unburnt layer was the same as the original composite. As such, the delamination in the unburnt layer was not taken into account, but could occur between different plies and severely weakened composite structure. On the other hand, the mechanical properties of intumescent mat (M1 and M2) with random glass fibre and mineral fibre were much lower than that of carbon fibre fabric in the laminate. However, the layers of M1 or M2 mats on the composite surface were combined with the CF prepreg laminate and considered as the same structure in the model, rather than as the individual layer with specific properties. Thus, the simulated flexural properties of composite should be higher than experimental value due to the extra "layers of carbon fibre fabric" on the composite surface. 

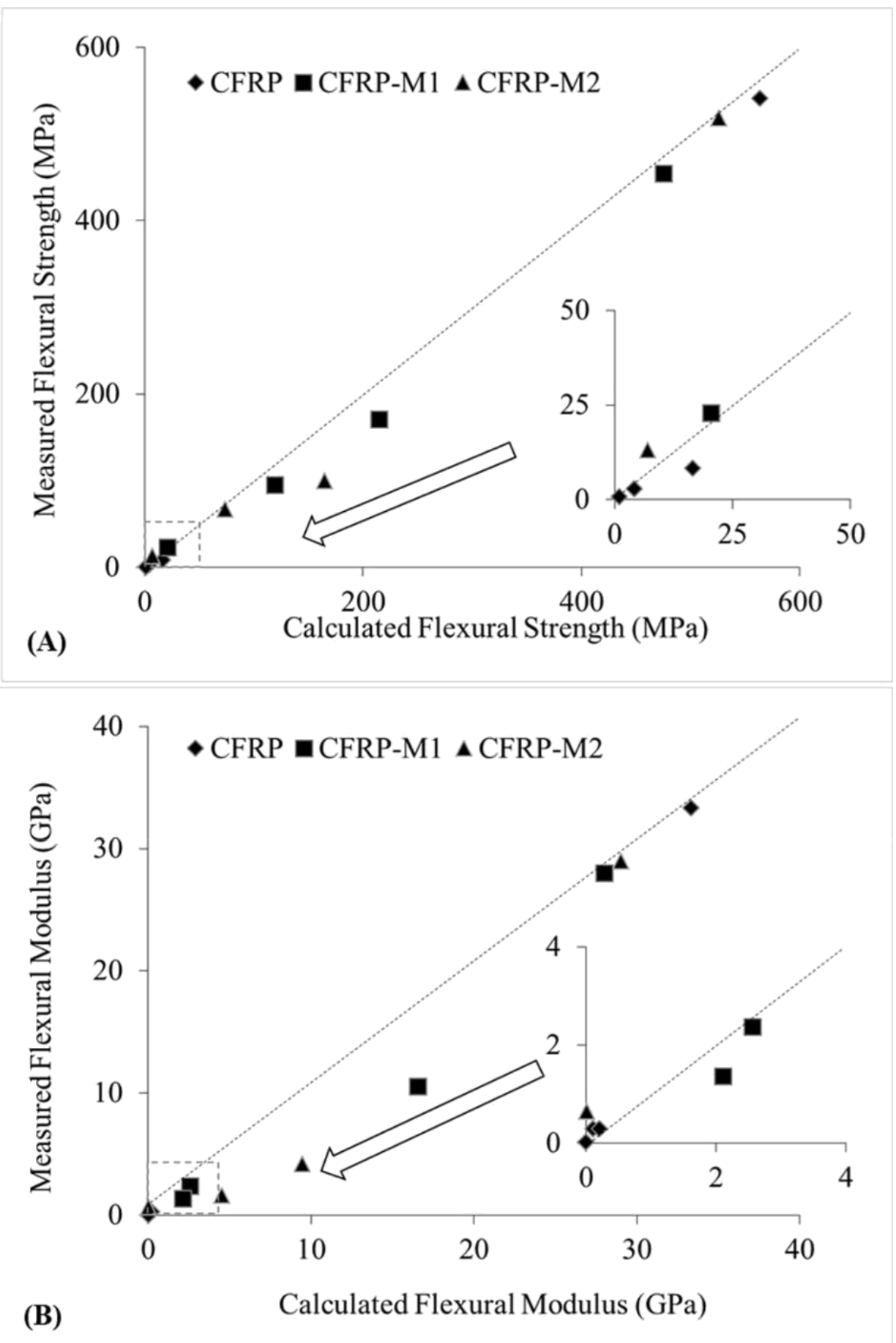

Figure 11: Comparison of the theoretical and measured post-fire flexural (a) modulus and (b) strength values of the composites with $50 \mathrm{KW} / \mathrm{m}^{2}$ heat fluxes. 


\section{Conclusion}

The flame retardant composite with the intumescent mats (M1 and M2) on the composite surface were analysed in this study, and the addition of M1 mats on the surface lead to better improvement in the fire performance of composite. The PHRR value was reduced by $61 \%$ and $39 \%$ for composite covered with M1 and M2 mats respectively, whereas the THR value were also reduced as much as $33 \%$ and $23 \%$. Additionally, the mechanical properties of composites were affected by intumescent mats which cover on the composite surface, the reduction in flexural strength and modulus was attributed to the increase of composite thickness with addition of intumescent mats.

The post-fire flexural properties of composite was characterised and the M1 mat also presented better retention of flexural strength and modulus when composite exposed to the heat flux. Compared with the simulated data using the mechanistic two-layer model, the measured values were close, but normally lower than the theoretical ones. This may be attributed to the limitation of the model where the delamination in the unburnt layer was not taken into account. Therefore, even though the current mechanistic models was a good approach to predict the performance of composite after the burning, the growing use of composites in fire risk situation still demanded the on-going development of fire structure models for laminate composite.

\section{Acknowledgements}

This work was carried out in ACC-UNNC Joint Laboratory in Sustainable Composite Materials. The authors would like to appreciate the support from AVIC Composites Corporation (Beijing) Science and Technology Co,. Ltd and Technical Fibre Products Ltd (UK). Additionally, authors also would like to appreciate the financial supported by Ningbo 3315 Innovation team Scheme "Marine Composites Development and Manufacturing for Sustainable Environment".

\section{Conflict of interest}

The authors wish to confirm that there are no known conflicts of interest associated with this publication. 


\section{References}

1. Bar M, Alagirusamy R and Das A. Flame retardant polymer composites. Fibers and Polymers. 2015; 16: 705-17.

2. Morgan A. Flame retardant fiber-reinforced composites. Handbook of Fire Resistant Textiles. Elsevier, 2013, p. 623-52.

3. Mangalgiri P. Composite materials for aerospace applications. Bull Mater Sci. 1999; 22: 657-64.

4. Rana S and Fangueiro R. Advanced composite materials for aerospace engineering: Processing, properties and applications. Woodhead Publishing, 2016. 5. Kiliaris P and Papaspyrides CD. Chapter 1 - Polymers on Fire. Polymer Green Flame Retardants. Amsterdam: Elsevier, 2014, p. 1-43.

6. Walters RN and Lyon RE. Flammability of polymer composites. Office of Aviation Research and Development, Federal Aviation Administration, 2008.

7. Lu S-Y and Hamerton I. Recent developments in the chemistry of halogen-free flame retardant polymers. Progress in polymer science. 2002; 27: 1661-712.

8. Laoutid F, Bonnaud L, Alexandre M, Lopez-Cuesta J-M and Dubois P. New prospects in flame retardant polymer materials: from fundamentals to nanocomposites. Materials Science and Engineering: R: Reports. 2009; 63: 100-25.

9. Rakotomalala M, Wagner S and Döring M. Recent developments in halogen free flame retardants for epoxy resins for electrical and electronic applications. Materials. 2010; 3: 4300-27.

10. Shaw S. Halogenated flame retardants: do the fire safety benefits justify the risks? Reviews on environmental health. 2010; 25: 261-306.

11. Papachlimitzou A, Barber JL, Losada S, Bersuder P and Law RJ. A review of the analysis of novel brominated flame retardants. Journal of Chromatography A. 2012; 1219: 15-28.

12. Babrauskas V, Fuoco R and Blum A. Chapter 3 - Flame Retardant Additives in Polymers: When do the Fire Safety Benefits Outweigh the Toxicity Risks? Polymer Green Flame Retardants. Amsterdam: Elsevier, 2014, p. 87-118.

13. Rothon R and Hornsby P. Chapter 9 - Fire Retardant Fillers for Polymers. Polymer Green Flame Retardants. Amsterdam: Elsevier, 2014, p. 289-321.

14. Suchitra M and Renukappa N. The Thermal Properties of Glass Fiber Reinforced Epoxy Composites with and without Fillers. Macromolecular Symposia. Wiley Online Library, 2016, p. 117-22.

15. Weil ED. Fire-protective and flame-retardant coatings-A state-of-the-art review. Journal of fire sciences. 2011; 29: 259-96.

16. Alongi J, Han $\mathrm{Z}$ and Bourbigot $\mathrm{S}$. Intumescence: tradition versus novelty. A comprehensive review. Progress in Polymer Science. 2015; 51: 28-73.

17. Feih S, Mouritz A, Mathys Z and Gibson A. Fire structural modeling of polymer composites with passive thermal barrier. Journal of fire sciences. 2010; 28: 141-60. 
18. Kandola BK, Bhatti $\mathrm{W}$ and Kandare E. A comparative study on the efficacy of varied surface coatings in fireproofing glass/epoxy composites. Polymer degradation and stability. 2012; 97: 2418-27.

19. Shi Y and Wang G. The novel silicon-containing epoxy/PEPA phosphate flame retardant for transparent intumescent fire resistant coating. Applied Surface Science. 2016; 385: 453-63.

20. Rowen JB. Composite Flame Retardant and Smoke Suppresssing Surfacing Mat. 2003.

21. Kandare E, Chukwunonso AK and Kandola BK. The effect of fire- retardant additives and a surface insulative fabric on fire performance and mechanical property retention of polyester composites. Fire and Materials. 2011; 35: 143-55.

22. Malucelli G, Carosio F, Alongi J, Fina A, Frache A and Camino G. Materials engineering for surface-confined flame retardancy. Materials Science and Engineering: R: Reports. 2014; 84: 1-20.

23. Zhang $X$, Wang R, Wang R, Yan X and Shi M. Universal evaluation of fire retardant properties of fiber mats by the optimal cone calorimeter. Textile Research Journal. 2018; 88: 892-903.

24. Kandola BK, Luangtriratana P, Duquesne S and Bourbigot S. The effects of thermophysical properties and environmental conditions on fire performance of intumescent coatings on glass fibre-reinforced epoxy composites. Materials. 2015; 8: 5216-37.

25. Liu J, Zhang Y, Peng S, et al. Fire property and charring behavior of high impact polystyrene containing expandable graphite and microencapsulated red phosphorus. Polymer Degradation and Stability. 2015; 121: 261-70.

26. Mariappan T. Recent developments of intumescent fire protection coatings for structural steel: A review. Journal of fire sciences. 2016; 34: 120-63.

27. Mouritz A. Post-fire flexural properties of fibre-reinforced polyester, epoxy and phenolic composites. Journal of materials science. 2002; 37: 1377-86.

28. Mouritz A, Gardiner C, Mathys $Z$ and Townsend C. POST-FIRE PROPERTIES OF COMPOSITES BURNT BY CONE CALORIMETRY AND LARGE-SCALE FIRE TESTING. ICCM13. Beijing, China2001.

29. Mouritz AP, Feih S, Kandare E, et al. Review of fire structural modelling of polymer composites. Composites Part A: Applied Science and Manufacturing. 2009; 40: 1800-14.

30. Mouritz AP and Mathys Z. Post-fire mechanical properties of marine polymer composites. Composite Structures. 1999; 47: 643-53.

31. Kandare E, Chukwudolue C and Kandola BK. The use of fire- retardant intumescent mats for fire and heat protection of glass fibrereinforced polyester composites: Thermal barrier properties. Fire and Materials: an international journal. 2010; 34: 21-38.

32. Abdou AA and Budaiwi IM. Comparison of thermal conductivity measurements of building insulation materials under various operating temperatures. Journal of building physics. 2005; 29: 171-84. 
33. Othman AM. Experimental Investigations of the Effect of Some Insulating Materials on the Compressive Strength, Water Absorption and Thermal Conductivity of Building Bricks. Jordan Journal of Mechanical and Industrial Engineering. 2010; 4: 443-50.

34. Papadopoulos AM. State of the art in thermal insulation materials and aims for future developments. Energy and Buildings. 2005; 37: 77-86.

35. Gibson A, Wright P, Wu Y-S, Mouritz A, Mathys Z and Gardiner C. Modelling residual mechanical properties of polymer composites after fire. Plastics, Rubber and Composites. 2003; 32: 81-90. 